\title{
Proof-of-Concept Manufacturing and Testing of Composite Wind Generator Blades Made by HCBMP (High Compression Bladder Molded Prepreg)
}

\author{
Final Technical Report for the U.S. Department of Energy \\ Grant Number DE-FG36-03G013140 \\ Reporting Period: 10/01/2003 - 03/31/2005 \\ Report prepared by: William C. Leighty \\ Alaska Applied Sciences, Inc. (AASI) \\ Box 20993 \\ Juneau, AK 99802
}

DOE Project Officers: Keith Bennett, Beth Dwyer

AASI Project Director: William C. Leighty

Phone Number: 907-586-1426

Fax Number: 907-586-1423

E-Mail: wleighty@earthlink.net

June 30, 2005 Rev 4 Oct 05

This report was prepared as an account of work sponsored by an agency of the United States Government. Neither the United States government nor any agency thereof, or any of its contractors/subcontractors, or any of their employees, makes any warranty, express or implied, or assumes any legal liability or responsibility for the accuracy, completeness, or usefulness of any information, apparatus, product, or process disclosed, or represents that its use would not infringe privately owned rights. Reference herein to any specific commercial product, process, or service by trade name, trademark, manufacturer, or otherwise, does not necessarily constitute or imply its endorsement, recommendation, or favoring by the United States Government or any agency thereof. The views and opinions of authors expressed herein do not necessarily state or reflect those of the United States Government or any agency thereof. 


\section{Table of Contents}

1.0 Introduction

2.0 Executive Summary and Project Status

3.0 Background

4.0 Procedure
4.1 Project procedure
4.2 Blade design

5.0 HCBMP Manufacture

5.1 HCBMP Process

5.2 Principles of blade design for HCBMP manufacture

5.3 Advantages of HCBMP manufacturing process

5.4 Detailed description of each blade or blade set

5.5 Materials and Lamination Schedule

5.6 Limitations and Disadvantages of HCBMP Process for Wind Generator Blades

6.0 Results

6.1 Project successes, from background

6.2 Project successes, other

6.3 Early commercialization success

6.4 Project failures, from background

6.5 Project failures, other

6.6 Power curve analysis

6.7 Further HCBMP process development work recommended

6.8 Further blade development work potential

7.0 Production Cost Estimates

7.1 Production cost model: hard tooling investment

7.2 Production cost model: total cost and selling price per blade

7.3 Estimated volume production cost per blade

8.0 Conclusion

Appendix Quatro Composites 30 J un 05 press release: Southwest Windpower order

\section{List of Tables}

Table 1. Blade Properties Summary

Table 2. Blade Disposition Log

Table 3. Materials and Lamination Schedule

Table 4. $\quad$ Sell Price Components

Table 5. Estimated Sell Price Detail

Table 6. Major Task Schedule 


\section{List of Figures}

Figure 1. $\quad$ Estimated Sell Price Per Blade

Figure 2. $\quad$ Estimated Sell Price Per Blade

Figure 3. $\quad$ Estimated Sell Price Per Blade, Aggregates

Figure 4. Estimated Sell Price Per Blade, Aggregates

Figure 5. Power Curves

Figure 6. $\quad$ Power Curves, including Shortened Blades

Figure 7. Instrumented test machine, B1 site, AASI windplant, Palm Springs, CA

Figure 8. NOMAD datalogger on instrumented test machine, B1 site.

Figure 9. Set \#1 on B1 test machine, AASI windplant, Palm Springs, CA. 6 Apr 04

Figure 10. CNC-machined and polished aluminum mold segments, ready for assembly

Figure 11. Prepreg layup in heated aluminum mold

Figure 12. Bladder installation

Figure 13. Demolding finished HCBMP blade at Quatro Composites (QC), Poway, CA

Figure 14. Root boxes filled with aluminum-filled epoxy mass casting

Figure 15. Tip twist angle inspection, with template

Figure 16. Install set \#1, B1 machine, AASI windplant, Palm Springs, CA., 5 April 04

Figure 17. Set \#1 tower clearance with turbine upwind of tower, on-line

Figure 18. Nov 04. Broken Set \#2 blade on B1 test site

Figure 19. Upwind (tension) side of Set \#2 blade buckling failure

Figure 20. Downwind (compression) side of Set \#2 blade buckling failure

Figure 21. Leading Edge D-Spar (LEDS ) of failed Set \#2 blade

Figure 22. $\quad$ Leading Edge D-Spar (LEDS ) of failed Set \#2 blade

Figure 23. Leading Edge D-Spar (LEDS ) of failed Set \#2 blade

Figure 24. 108" from root end of failed Set \#2 blade

Figure 25. Miniature color TV camera, mirror, and fluorescent light for inspection

Figure 26. Inspection videocamera enters blade shell SN 13

Figure 27. Blade SN 13, Set \#3, 138" from root end (FRE) of blade, showing "bumps"

Figure 28. I Inboard ends of LEDS's for Set \#3

Figure 29. SN 12, Set 3, as-molded

Figure 30. Hub-mounted digital videocamera for viewing whole blade

Figure 31. Set \#3 typical leading edge (LE) shows mid-span foam dam and 0.068 " diam nylon

Figure 32. Set \#3 installed on B1 test machine

Figure 33. Blade set \#1 with $\sim 1 \mathrm{~m}$ removed from tips

Figure 34. Flap stiffness and ultimate flap strength test, SN1, 4 Mar 04

Figure 35. Torsional stiffness measurement with load cell and couple.

Figure 36. Windpower05 poster

Figures A-D. Blade design 


\subsection{I ntroduction}

Project Title: Proof-of-Concept Manufacturing and Testing of Composite Wind Generator Blades Made by HCBMP (High Compression Bladder Molded Prepreg)

DOE Award Number: DE-FG36-03G013140

Document Title: Final Report

Period Covered by Report: 1 Oct 03 to 31 Mar 05

Date of Report: 30 J une 05

Recipient: Alaska Applied Sciences, Inc. (AASI)

Box 20993, Juneau, AK 99802-0993

Technical Contact: William C. Leighty, Principal, AASI

907-586-1426 FAX: 907-586-1423

wleighty@earthlink.net

Working Partners: Grantee: AASI

Principal contractor to AASI: Quatro Composites, Inc., (QC)

12675 Stowe Dr., Poway, CA $92064 \quad 858.513 .4300$

Contacts: Doug Roberts, Ken Gamble

\section{Cost-Sharing Partners: AASI}

DOE Project Team: DOE HQ Program Manager - Jim Ahlgrimm

DOE Field Project Officers - Keith Bennett, Beth Dwyer

NWTC Coordinator - Trudy Forsyth

Associated files: These files will be NOT transmitted with this final report file, but are available from AASI to supplement this report:

1. WindTurbineBlade-HCBMP-1-ELS-23Feb04.pdf

2. WIND TURBINE BLADE, BLADDER MOLDED.pdf

3. AASI-QC-SellPriceEstimate-310ct04.xls

Patents: We do not expect any patents to proceed from this project.

DOE Program Objective: Lower COE from small $(<100 \mathrm{~kW})$ wind generators in low windspeed installations (class 3).

Project Objective: This project's goal is to lower the long-term cost of energy (COE) from small wind generators by:

- Lowering the capital cost of volume production of any small wind turbine blade design within the range of about $5-50 \mathrm{~kW}$ nameplate;

- Improving the reliability of wind turbine blades by improving manufacturing process simplicity, repeatability, and quality. 


\section{Publicity:}

- Magazine articles:

o "Small-scale Blade Manufacturing via Bladder Molding", Composites Technology, Feb 05, pp 35-39

o "Segmented Mold Slashes Development Cost", High-performance Composites, Mar 05, pp 60-62

- Conferences:

o Windpower04, AWEA, Chicago, May 04: poster

o Windpower05, AWEA, Denver, May 05: paper and poster

- Press release, Quatro Composites, Aug 05: Purchase order from Southwest Windpower for HCBMP blades, 2.5 m length, for "Whisper" wind generator.

\subsection{Executive Summary and Project Status}

1. Tables 4 and 5. The HCBMP process worked well for the $5.7 \mathrm{~m}$ (225") long blade designed, tooled, and built for this project, except that we did not mold a single blade with a readyto-paint surface finish. If this problem is solved, subcontractor Quatro Composites (QC) estimates selling price for 10,000 blades per year, ready to install, made in Poway, CA, is about $\$ 1,500$; price for the blade made in Mexico is about $\$ 1,200$. Deleting the LEDS, if not required for blade stability, saves $\sim \$ 100$. This does not include design and tooling amortization.

2. Without advice from small wind generator manufacturers about competitive processes, we cannot conclude whether the estimated costs in (1), above, represent an important improvement in blade production economics.

3. The blade design and tooling fabrication processes were economical, flexible, and fast.

4. The blade design was well-suited to HCBMP, and to this research project.

5. Ed Salter, Salter \& Associates, Oceanside, CA, made a very valuable pro bono contribution of blade design and engineering assistance in project's early phases.

6. Tables 1, 2, and 3. We achieved very high torsional stiffness and ideal flap stiffness with the lamination schedule featuring a high content of carbon 45 / 45 plies, and a small quantity of glass zeros for material economy.

7. Subcontractor QC performed well; their expertise in tooling and HCBMP is outstanding, and probably rare; their proximity to AASI test site was valuable.

8. We operated three blade sets in San Gorgonio Pass, Palm Springs, CA on one instrumented $50 \mathrm{~kW}$ (drive train nameplate) wind generator, 135 turbine rpm, downwind, passive yaw, built in '85-86 as trade name "Storm Master" by Wind Power Systems, Inc., San Diego, CA.

9. We captured extensive digital video of set \#1 blades in normal and in unusual operating conditions, both from the ground and from a hub mount viewing a single blade.

10. We captured power curve data on several blade sets, in several configurations.

11. The AASI windplant is a good test site, with readily-available field service help from enXco, occasional strong windspeed episodes, and a benign year-round climate.

12. We cannot test blades for long-term fatigue life because the full-length blades will not operate on the AASI windplant machines, in high windspeed, without overpowering the drive train and causing unacceptable yaw instability.

13. AASI fulfilled its matching resource obligations, in cash and in-kind.

14. Project budget was fully expended.

15. AASI will advise DOE, long-term, of anything learned from field operation of the three cutdown ( 39 " removed from tips) blade sets.

16. We identify the advantages of the HCBMP manufacturing process.

17. We recommend further research and process development on HCBMP. 


\section{Project Status at 15 May 05}

Blade sets \# 1, 2, and 3 have been shortened, by removing $383 / 4$ " $(\sim 1 \mathrm{~m})$ from the tip of each blade, installing a tip plate on each blade, rebalancing the set, and installing the set on an operating machine at the AASI Palm Springs windplant, for long-term durability testing. Set \#1 on A26; set \#2 on B1; set \#3 on A34.

The full-length blades would not allow the machine to operate in stable, down-wind, on-line conditions. This is a cut-and-try effort to derive long-term value from the blades; only field experience will reveal stable machine operation and blade durability.

Large tooling (aluminum mold, airspring press, bladder dipping mandrel) is in long-term storage at QC. Small tooling, tools, and fixtures are in long-term storage at AASI facilities in Palm Springs, $\mathrm{CA}$ and in Juneau, AK.

\subsection{Background}

Wind turbines optimized for Class 3 resources will have a higher ratio of turbine swept area to drive train power rating than wind turbines optimized for more energetic wind regimes. Therefore, blades will be a larger fraction of total wind turbine system capital cost. We need to emphasize low-cost blade production methods via proof-of-concept blade fabrication and extensive field testing.

We intended to prove, via pilot production and extensive field testing of sets of operating blades, the low cost high compression bladder molded prepreg (HCBMP) blade manufacturing process. The field testing will be done at an extant windplant, owned by AASI, of 14, $40 \mathrm{~kW}$ wind generators, in the energetic wind regime of San Gorgonio Pass, CA, near Palm Springs, CA, in order to:

1. Fully stress the blades and accelerate their life testing;

2. Validate and improve the HCBMP manufacturing process for small wind turbine blades;

3. Accurately estimate, based on the experience in 1 and 2 , high-volume production cost for this blade;

4. Provide a model by which HCBMP tooling and volume production costs may be accurately estimated for any other blade design in the "small turbine" realm.

\section{Project Emphasis on Manufacturing Process, not Blade Design}

This project's objective is investigating and demonstrating the potential of the HCBMP manufacturing process to lower the cost of high-quality, long-service-life, all-composite blades for small wind generators, not to optimize blade design for the wind generator on which these experimental blades will be field tested.

\subsection{Procedure}

\subsection{Project Procedure: Tables 1, 2, and 6}

1. Design a new blade for AASI's 14-machine windplant in San Gorgonio Pass, Palm Springs, $\mathrm{CA}$, suitable for proof-of-concept manufacturing via HCBMP. (Serial number $\mathrm{X}=\mathrm{SN} X$ )

2. Translate the blade design from solid modeling software to tool paths for $\mathrm{CNC}$ mill and design mold; innovative segmented design whereby the $20 \mathrm{ft}$ long aluminum mold is made on a small CNC mill in short sections dovetailed together. See Fig. 10 and 7.1, below.

3. Machine aluminum mold blocks in CNC mill; hand finish by sanding and polishing; condition with release; assemble mold on roller table next to airspring press, in loading position. 
4. Design and build airspring press for confining and heating the aluminum mold.

5. Produce first two blades, to experiment with process; test SN 2 blade to measure static properties of torsion and flap stiffness, lead-lag and flap resonance; test to flap failure.

6. Modify lamination schedule, based on results of (5)

7. Machine aluminum mold for 113" long Leading Edge D-spar (LEDS) (mold makes set of 3 parts)

8. Make female wet-layup fiberglass mold from LE of SN 1, with which to mold the inboard LEDS structures from $10 \mathrm{pcf}$ urethane foam.

9. Produce "ship set" \#1, including LEDS structures in the HCBMP molding process.

10. Test fly set \#1 at B1 instrumented test machine, AASI windplant, Palm Springs:

a. Measure power curve at several blade pitch settings;

b. Confirm flap stiffness is ideal for this "soft" turbine design;

c. Confirm blade set is robust in stressful operating conditions: high windspeed, overspeed emergency shutdown, turbine running upwind of tower;

d. Confirm freedom from flutter, system vibration, and tip noise;

e. Collect digital video, from ground and from hub-mount.

11. Build and install set \#2, using different manufacturing process than set \#1: rather than molding-in the LEDS structures in HCBMP process, hollow blade shells were molded and outboard LEDS structures were epoxy-potted in place.

12. Motivated by the failures of two set \#2 blades, set \#3 was built with stiffener panels. See 6.5 and Figs. 18-23, below.

13. Set \#3 test flown with airfoil modifications, attempting to investigate and accomplish stall regulation.

14. Blade sets \#1, 2, 3 cut down, by removing 38 3/4" from tips, in attempt to achieve stable system operation (on-line, hub latched) in high windspeed and to obtain long-term operating experience on all the flyable blades produced by this project.

\subsection{Blade Design}

See Figures A-D, pp 41-44. Blade was designed by Ed Salter \& Associates (ESA), Oceanside, CA, in SolidWorks, proceeding from "Propfile" optimization of airfoil selection, chord, taper, and twist. This design remains the property of ESA, who have supplied this design, for this project, pro bono. Blade design criteria:

1. Length overall $(\mathrm{LOA})=225$ to $231^{\prime \prime}=5.7 \mathrm{~m}$. Machine hub radius $=0.43 \mathrm{~m}$. Turbine diameter $=2(6.23 \mathrm{~m})=12.5 \mathrm{~m}$

2. Power curve stall regulated at $40-50 \mathrm{~kW}$

3. Turbine self-starting in $15-20 \mathrm{mph}$ windspeed

4. "Soft" , "centrifugally-stiffened" turbine requires:

a. Correct flap stiffness, to shed stochastic loads but not deflect into the tower in extreme operational events;

b. A dense leading edge D-spar (LEDS) embedded in outer half of blade length, to:

i. place chordwise center of mass ahead of (toward LE) the quarter-chord point, to prevent torsion-flap and whirl flutter; see flutter discussion by Riso, Denmark; ${ }^{1}$

ii. centrifugally stiffen the rotor at operating rpm.

Flap stiffness and LEDS design details were supplied by ESA. See LEDS "embed" in 5.4.

5. Use NREL 822 and 823 airfoils for resistance to power curve degradation from leading edge (LE) dirt (roughness; soiling); these airfoils recommended by NREL for this project.

6. Rectangular cross-section root box for through-bolting blade to hub blade mount

\footnotetext{
${ }^{1}$ Models for Wind Turbines - a Collection, A. Baumgart, Riso-R-1352(EN), Risø National Laboratory, Roskilde, Denmark, February 2002
} 


\subsection{HCBMP Manufacture}

\subsection{HCBMP Process}

Plies of unidirectional prepreg (impregnated with catalyzed epoxy resin) "tape", 0.005 " thick, are cut and stacked to achieve the required lamination schedule. Glass and carbon plies may be mixed. The ply stacks are degassed and consolidated for several hours in vacuum bags. The two-part aluminum mold is preheated to $\sim 100 \mathrm{~F}$ in the airspring press which will be used to cure the part. Ply stacks are laid in the heated mold; multiple stacks may be needed to achieve the required lamination schedule. A heat-resistant rubber bladder, slightly smaller than the part's interior crosssection, is laid in the mold bottom before the mold top is installed.

The loaded mold is closed and slid into the airspring press, which is now heated to curing temperature of $\sim 275 \mathrm{~F}$. The airspring press is clamped into the mold with $\sim 125 \mathrm{psi}$ applied to the clamping firehoses. The internal bladder is slowly inflated to $\sim 125 \mathrm{psi}$ as the prepreg resin softens, compacting the prepreg plies upon each other and against the mold surface at this high pressure. After $\sim 1$ hour cure, the bladder is depressurized; the airspring press is depressurized; the mold is withdrawn and opened; the cured part is removed. Mold is now ready for another part layup-mold cycle.

\subsection{Principles of Blade Design for HCBMP manufacture: Figures A-D.}

1. Single cavity hollow blade, single bladder. Internal structures limited to those:

a. Easily co-molded with the blade shell in the HCBMP process; may be full-span

b. Installed in root box boltup region, for crush load transfer; may be potting

2. All-composite, molded entirely of prepreg tape; fibers may be any material

3. Surface ply is tape, vulnerable to tow pullout of these uni fibers: must be soon painted

4. No small radii nor abrupt shape transitions in cross-section

5. Maximum blade length: based on our limited experience, blades longer than $6 \mathrm{~m}$, with chord $>0.3 \mathrm{~m}$, would be a challenge. This blade is by far the largest HCBMP part that QC has made.

\subsection{Advantages of HCBMP manufacturing process}

1. Modest tooling cost: small mold cross-section, machining in aluminum from $3 D$ part shape file (SolidWorks, ProEngineer, etc.), airspring press, external mold heaters;

2. Female aluminum tooling results in excellent surface finish; minimum preparation for painting;

3. Low labor cost: modest skill required, prepreg easy to handle, no liquids, rapid cycle time (2-3 hours per part), ;

4. Low material cost: no liquids, low waste, prepreg widely available and economical in wide variety of fibers and properties, fiber: resin ratio;

5. Prepreg material inherent advantages:

a. Fiber is pre-impregnated with catalyzed epoxy resin;

b. Controllable fiber: resin ratio, via prepreg material specification;

6. Fatigue-resistant material: laminate built entirely of tape (unidirectional, nonwoven fiber plies, $0.005^{\prime \prime}$ thick)

7. Safety and health benefits: no liquids, dry fiber, or dust;

8. Minimized process variability; consistent properties of parts;

9. Minimum material waste; 
10. High compaction ( 100 psi bladder pressure) results in high-quality composite; minimum voids for long fatigue life;

11. Blade mechanical properties easily engineered from inside-out, by adjusting lamination schedule.

\subsection{Detailed description of each blade or blade set: Figures A-D; Tables 1, 2}

SN 1: First blade built with full lamination schedule.

SN 2: Static and dynamic properties tests; ultimate flap deflection and strength; test to flap failure in two places

SN 3, 4, 5: Set \#1, first flyable set. LEDS molded into blade in HCBMP layup and curing process. Extensive flight testing proved:

a. Short-term durability in variety of difficult operating conditions; long-term durability unknown;

b. Adequately-accurate power curve;

c. Will not allow stable operation of the wind generator: overpowers drivetrain in high windspeed, causing automatic shutdown; unlatches hub, causing machine to drop offline, yaw upwind, and occasionally return to stable, on-line operation running upwind of tower

d. Durability of molded-in LEDS structures, inboard and outboard

e. Durability of root box potting with aluminum-filled epoxy

f. Freedom from flutter

g. Ideal flap stiffness

SN 6, 7, 8: Set \#2, second flyable blade set. LEDS potted into blade post-HCBMP process. Two blades failed, with turbine in parked position, in $\sim 60 \mathrm{mph}$ wind, installed on B1.

SN 9, 10: Replacement blades for SN 6, 7, to restore set \#2. Both had problems in HCBMP process, but were repaired. Cut down by removing 38 3/4" from tip of each blade, in attempt to make blade durable enough for operation.

SN 11, 12, 13: Set \#3, third flyable blade set. Spanwise stiffener panels molded into top and bottom surfaces of blades in the HCBMP process. LEDS's potted into blades post HCBMP process: very time-consuming; probably not a production process. Flight tested briefly on B1. Blade shape modified, attempting to achieve stall regulation, with short-term test results.

\subsection{Materials and Lamination Schedule: Table 3}

The blade is laid up of identical "stacks" of 12 plies each @ 0.0053" cured thickness each. Each stack is vacuum-bagged for $\sim 12-24$ hours to consolidate the material and remove air and moisture. The blade wall is 1 stack thick at the outer $\sim 50 \%$ of span, 5 stacks thick at the root box. Number of +45 plies will always equal number of -45 plies.

The +/- 45 plies are all carbon, to achieve the highest possible torsional stiffness, to prevent classic torsion-flap flutter. The $\mathbf{S 2}$ glass prepreg is used only in spanwise unidirectional placement, to:

1. limit the flap stiffness of the blade to achieve the desired "soft" , centrifugally-stiffened turbine;

2. reduce material cost.

Increasing the ratio of glass to carbon prepreg might lower total blade cost slightly, but must not increase laminate thickness and bulk volume, which trap more air and moisture in the ply stacks, exacerbating the surface finish problem. 


\subsection{Limitations and Disadvantages of HCBMP Process for Wind Generator Blades}

1. Very difficult to include internal structures: spars, ribs, root box compression block, etc.

2. TE small angle and small radius cannot be shaped by the bladder; require "tows" (unidirectional prepreg bundles) and / or foam filler strip to increase curvature radius to accommodate bladder minimum operating radius. This adds undesirable mass to TE. TE near-zero thickness is difficult to fabricate in any composite process. Good compaction must be achieved here, on the neutral axis, to achieve long fatigue life. TE is a de facto glue joint.

3. Mismatch between aluminum mold and composite part in coefficient of thermal expansion (CTE) requires rapid demolding of cured blade.

4. Surface finish is easily compromised by trapped air and water (as vapor or liquid); requires costly post-molding finishing to prep for painting; exacerbated by increased ply thickness; requires vacuum-degassing and -debulking before loading ply stacks into mold.

5. Long, thin aluminum mold is flexible and fragile; requires reinforcing frame on top half and careful handling.

6. Cost of prepreg material is higher than cost of dry reinforcements plus wet resin.

\subsection{Results}

\subsection{Project Successes, from Background (above)}

1. Figure 34. One sample blade, SN 1, was tested to flap failure: 1,000 lbf applied at 160" from root end, resulting in 40" deflection at 160".

2. Static properties measured: Flap and torsional stiffness; tip twist; weight; CG; flap and lead-lag resonant frequencies

3. HCBMP process was validated for small blades, except for surface finish; further development work is needed to eliminate dry spots where air and / or steam are trapped during the cure process at $\sim 275$ F. See Fig. 29. QC believes this is a tractable problem.

4. We estimate volume production cost, under several assumptions, based on QC experience tooling for and building 13 blades.

5. We present a simple volume production cost model. We are unable to compose a useful tooling cost model.

\subsection{Project Successes, Other}

1. Figures 5 and 6: Power curves measured; not a principal project objective. See 6.5.

2. Digital video made of sets \#1 and 3 in operation, with camera on:

a. Ground, to observe blade tip tracking and hub balance;

b. Rotating hub shaft, to observe an entire blade;

c. Rotating hub shaft, to observe blade mount position, watching for hub unlatch

3. Several variations in manufacturing method, within HCBMP process, were tried, although we built too few blades to confidently assess the value of each:

a. Molding-in the LEDS structures during HCBMP cure;

b. Molding hollow blades with post-cure installation of outboard LEDS by epoxy potting;

c. Stiffener panels molded-in to top and bottom surfaces during HCBMP layup and cure.

d. Locating blade mounting hole pattern further toward LE of blade, in attempt to prevent hub unlatching in high windspeed, although unlatching was not prevented. 


\subsection{Early Commercialization Success}

See Appendix, Quatro Composites 30 Jun 05 press release announcing Southwest Windpower (Flagstaff, Arizona) purchase order for development and production of the redesigned Whisper 500 wind generator blades using Quatro's HCBMP process. This order is probably a direct result of the subject "proof of concept... field testing" project.

\subsection{Project Failures, from Background (above)}

1. Blade design did not achieve self-start or stall-regulation criteria; "PropFile" design method failed to accurately predict power curve in low and high windspeed regions.

2. Full-length blade would not operate on the AASI windplant machines, because in high windspeeds:

a. Drive train is overpowered; controller shutdown at $90 \mathrm{~kW}$ software setpoint;

b. Latching, passive centrifugally-governed hub is released by some unknown combination of vibration and pitching torque on the hub blade mount

3. Because of 1 and 2, above, long-term fatigue life of blades cannot be investigated

4. Accuracy of our volume production cost estimates is limited, because:

a. We were able to build only 13 blades, within budget, without fully investigating manufacturing process variations;

b. We were unable to build a single blade with surface finish good enough to prime and paint with minimal handwork

\subsection{Project Failures, Other: Table 1}

1. Failure of two blades from set \#2, from buckling in high windspeed while turbine was parked, caused QC to introduce 1/8" thick stiffener panels in top and bottom surfaces of set \#3, in the HCBMP molding process: a low-cost solution. Set \#2 had no inboard foam LEDS, as set \#1 did, so set \#2 blades failed at the stress concentration immediately inboard of the end of the steel shot - epoxy LEDS. See Figs. 18-24.

2. SN10 blade was built omitting one prepreg material ply stack, the shortest one in the root box region, on tension side (bottom) of blade: manufacturing error during layup. This blade has been cut down, so this error is probably not important to blade operation or service life.

3. Tip twist varies more than expected; averages $\sim 8.5$ degrees instead of designed 8.0 .

\subsection{Power Curve Analysis: Figures 5 and 6}

Beyond the scope of this project, we investigated power curve of the blade sets tested on B1 site instrumented machine, using:

1. Meteorological tower 2.5 rotor diameters upwind of the wind generator tower, with dual Maximum 40 anemometers, direction and slope vanes;

2. Ohio Semitronics calibrated kW transducer, with matched current transformers (CT's);

3. NOMAD datalogger, averaging at 1 minute.

We discovered from measured power curves that:

1. We did not achieve our low windspeed goal of $20 \mathrm{~kW}$ at $20 \mathrm{mph}$;

2. Stall regulation, nor onset thereof, was not evident at high windspeed on sets \#1 or \#3 Late in the project we experimented with modifications to the blade shape, attempting to induce stall regulation, as shown in Figures 5 and 6 . With limited on-line data, we concluded that:

1. The mid-span foam dam, attempting to limit spanwise flow, had negligible effect;

2. The full-span LE fishline, captured under $3 M$ clear urethane paint protection film, shifted the power curve slope downward and introduced some power curve rolloff at $\sim 40 \mathrm{~kW}$. Later in the project, we removed $\sim 1 \mathrm{~m}$ from the tips of sets 1,2 , and 3 , in order to be able to fly the blades for extended fatigue life investigation. We obtained a large dataset for power curve for set \#2 on the instrumented B1 test machine: See Figure 6, orange curve. It is far below the other 
power curves at low windspeed; rolls off at $\sim 50 \mathrm{~kW}$, apparently due to stall regulation. The shortened blades are self-starting on 20-30 mph windspeed. Shortening the blades thus allows long-term operation on the AASI windplant machines.

\subsection{Further HCBMP Process Development Work Recommended}

In order to validate the estimated production costs presented here, and to pursue further cost reductions, QC recommends building $\sim 50$ process development blades, probably with a high scrap rate, to investigate:

1. Surface finish improvement, trying:

a. Peel ply applied to mold before any prepreg is installed

b. Surfacing resin sprayed into the mold before any prepreg is installed

c. Varying aluminum mold preheat temperature, to avoid air-trapping premature cure

d. Resin-rich ply(ies) in outer layer, to better wet outer fiber ply

e. Add bleeder channel to mold, to vent air trapped between mold halves

2. Digitally-controlled robotic cutter for precise production of prepreg plies and stacks: more accurate mold filling, improve consistency, consequently surface finish, especially at TE region

3. LEDS co-molding variations, to install both outboard and inboard LEDS structures

4. Tooling: Set of hardened steel LE inspection and shaping tools, for ex-mold deflash

5. Tooling: Single-operator crane for lifting mold top, for installation and removal

6. Tooling: Experiment with different bladder materials and bladder cross-section, to prolong life, improve removability, and reduce wrinkling.

7. Experiment with molded-in foamcore panels for top + bottom surface stiffening, per Set \#3

8. Root box structural reinforcement, alternative to potting with aluminum-filled epoxy:

a. Hard urethane potting

b. Install compression beam(s) with structural adhesive

9. Vary bladder pressure and mold temperature profiles with time

\subsection{Further Blade Development Work Potential}

The AASI test site is amenable to further investigation of blade aerodynamic performance, by making more blade sets to investigate:

1. Reducing mass of the LEDS until torsion-flap or whirl flutter occurs

2. Modify airfoil behavior by adding small structures to the blade - Gurney flap, LE stall strip, spanwise flow fence, etc. - to attempt stall regulation and power curve shaping, as measured from automated data collection. Recent paper by Jim Tangler, et al, offers some guidance. $^{2}$

3. Install a matrix of telltale yarns on an operating blade; video the blade from a hubmounted, rotating camera a good distance downwind on the axis of rotation. This will provide flow separation information to guide investigation in (2), above.

\subsection{Production Cost Estimates}

\subsection{Production Cost Model: Hard Tooling I nvestment}

Based on our experience on this project, and on QC general experience, we are unable to develop a useful model for predicting hard tooling time and cost. QC mold machining is limited to 36"

\footnotetext{
${ }^{2}$ Wind Turbine Post-Stall Airfoil Performance Characteristics Guidelines for Blade-Element Momentum Methods, J. Tangler, J.D. Kocurek, AIAA Annual Meeting, Jan 05.
} 
long sections in its CNC machine. Estimating a scaling factor for cost vs blade size is not now realistic. We offer discussion of the following tooling components.

Mold design engineering Details of how mold is to be executed from the solid model design. Fairly constant; independent of blade size. Depends on whether conversion is necessary from source design file (SolidWorks, ProEngineer, etc.).

\section{Multi-section aluminum mold, assuming: (see Publicity, above)}

- The design has been converted to tool paths for the CNC and ready to cut metal;

- Mold consists of 36" - long sections, compatible with popular, low-cost CNC's Mold cost components:

1. Raw aluminum blocks from supplier. Cross-sectional area determined by blade design, primarily maximum chord and twist. Volume, thus weight, determined by product of (mold cross-section) $x$ (blade length). Mold cross-section is about 1 inch greater, on all sides, than the dimensions of the rectangle that would enclose plan view of all blade cross-sectional profiles along its complete length.

2. CNC machine time: block preparation (surface planing, holes for alignment pins and other assembly and lifting fixtures)

3. CNC machine time: mold cavity cutting, top + bottom. Determined by (total amount of metal to be removed) / (metal removal rate) $x$ (CNC hourly rate). Approximation might be that 35 - $50 \%$ of the aluminum block volume is to be removed?

4. Hand finishing: sanding and polishing and release-conditioning. This cost varies directly with the mold surface area to be finished.

\section{Airsping Press}

1. Welded press structure: determined by mold dimensions (I $x w \times h)$

2. Alum platens, top + bottom: determined by mold footprint ( $\mathrm{x}$ w)

3. Firehose mold compression assembly: determined by mold footprint ( $\mathrm{x}$ w)

4. Heating system: calrod heaters, thermocouples, controllers, power relays, wiring

\section{Mold Handling Equipment}

1. Roller table

2. Lifting system: crane(s) + strongback frame for top half of mold

\section{Other Hard Tooling}

1. Mold dipping mandrel

2. LE inspection and shaping tool set

Total Hard Tooling I nvestment Sum of the above components 


\begin{tabular}{|c|c|c|c|c|c|c|c|c|c|c|c|c|}
\hline $\begin{array}{l}2004 \\
\text { Mold } \\
\text { Date }\end{array}$ & SN & $\begin{array}{l}\text { Fly- } \\
\text { abl } \\
\text { Set } \\
\#\end{array}$ & $\begin{array}{l}\text { Tip } \\
\text { Twist } \\
\text { Deg }\end{array}$ & $\begin{array}{l}\text { Raw } \\
\text { Tip } \\
\text { Wt, g }\end{array}$ & $\begin{array}{l}\text { Balance } \\
\text { d } \\
\text { CG } \\
\text { Inches } \\
\text { FRE }\end{array}$ & $\begin{array}{l}\text { Unbalance } \\
\text { Balanced } \\
\text { Total } \\
\text { Blade } \\
\text { Wt, g }\end{array}$ & $\begin{array}{l}\text { Flap } \\
\text { Res } \\
\text { Freq, } \\
\text { cpm }\end{array}$ & $\begin{array}{l}\text { Lead- } \\
\text { lag } \\
\text { Res } \\
\text { Freq, } \\
\text { cpm }\end{array}$ & $\begin{array}{l}120 " \\
\text { FRE } \\
\text { Flap } \\
\text { Stiff }\end{array}$ & $\begin{array}{l}120 " \\
\text { FRE } \\
\text { Tors } \\
\text { Stiff }\end{array}$ & $\begin{array}{l}220 " \\
\text { FRE } \\
\text { Flap } \\
\text { Stiff }\end{array}$ & $\begin{array}{l}220 " \\
\text { FRE } \\
\text { Tors } \\
\text { Stiff }\end{array}$ \\
\hline $3-2$ & 1 & no & ND & ND & ND & 18450-unb & ND & ND & 31 & 88 & 3 & 24 \\
\hline $3-12$ & 2 & no & ND & ND & ND & 25590-unb & 108 & 350 & 33 & 125 & 3.3 & 44 \\
\hline $3-23$ & 3 & 1 & 8.75 & 12835 & 100.4 & 28486-unb & 69 & 278 & 22.6 & ND & 2.1 & ND \\
\hline $3-24$ & 4 & 1 & 8.63 & 12884 & 99.6 & 28028-unb & 68 & 264 & 22.3 & ND & 2.1 & ND \\
\hline $3-25$ & 5 & 1 & 8.55 & 12840 & 101.5 & 28221-unb & 68 & 264 & 23.0 & ND & 2.2 & ND \\
\hline $9-15$ & 6 & 2 & 8.68 & 11821 & 121.2 & 27875-unb & 66 & 270 & 23.5 & 120 & 2.0 & ND \\
\hline $9-16$ & 7 & 2 & 9.05 & 11848 & 121.8 & 28094-unb & 66 & 297 & 22.5 & 130 & 1.8 & 38 \\
\hline $9-17$ & 8 & 2 & 8.68 & 11467 & 121.5 & 27243-unb & 65 & 263 & 20.8 & 160 & 1.8 & 38 \\
\hline$?$ & 9 & $2 *$ & ND & ND & ND & ND & ND & ND & ND & ND & ND & ND \\
\hline$?$ & 10 & $2 *$ & ND & ND & ND & ND & ND & ND & ND & ND & ND & ND \\
\hline $12-15$ & 11 & 3 & 8.36 & 12621 & $1007 / 8$ & 28273-bal & 66 & 275 & 20.4 & ND & 1.95 & ND \\
\hline $12-16$ & 12 & 3 & 8.59 & 12600 & $991 / 8$ & 28689-bal & 66 & 300 & 23.0 & ND & 1.92 & ND \\
\hline $12-17$ & 13 & 3 & 8.83 & 12567 & $1003 / 8$ & 28539-bal & 67 & 300 & 21.8 & ND & 1.85 & ND \\
\hline
\end{tabular}

Table 1. Blade properties summary.

Notes: 1 . * set \#2 replacement blades

2. $\mathrm{ND}=$ no data; $\mathrm{FRE}=$ from root end, distance

3. Flap stiffness $=\mathrm{lbf} /$ inch deflection

4. Torsional stiffness $=\mathrm{lbf} /$ deg deflection. Couple; Figure 35; arms longer after SN1

5. 5,000\# load cell used for all deflection tests

\begin{tabular}{|lll|}
\hline SN & $\begin{array}{l}\text { Flyable } \\
\text { Set \# }\end{array}$ & \multicolumn{1}{c|}{ Comments } \\
\hline \hline 1 & no & Process development: 1" wood dowel LEDS \\
2 & no & Process development: flap test to destruction \\
3 & 1 & LEDS molded in (inboard foam): poor surface, repaired, flight test OK \\
4 & 1 & LEDS molded in (inboard foam): poor surface, repaired, flight test OK \\
5 & 1 & LEDS molded in (inboard foam): poor surface, repaired, flight test OK \\
6 & 2 & LEDS potted into molded shell: flap failure, broke in 60 mph wind on B1 \\
7 & 2 & LEDS potted into molded shell: flap failure, broke in 60 mph wind on B1 \\
8 & 2 & LEDS potted into molded shell: cutoff tip \\
9 & $2 *$ & Replacement for SN 6: blown bladder in molding; cutoff tip \\
10 & $2 *$ & Replacement for SN 7: bladder broke at removal; chunks in blade; cutoff tip \\
11 & 3 & Molded stiffener panel; LEDS potted into molded shell; flight test OK \\
12 & 3 & Molded stiffener panel; LEDS potted into molded shell; flight test OK \\
13 & 3 & Molded stiffener panel; LEDS potted into molded shell; flight test OK \\
\hline
\end{tabular}

Table 2. Blade disposition log. * set \#2 replacement blades

Table 1 and 2 Notes:

1. Set 2, SN 6 and 7 blades failed in flap (buckled and broke) just inboard of LEDS, while installed on B1 test machine, with rotor parked, in $\sim 60 \mathrm{mph}$ wind. * SN 9 and 10 were built to replace them.

2. Set 3 construction: molded shell; LEDS installed in shell with LEDS epoxy potting. Data is for finished blade, including LEDS

3. SN10 was built, in error, omitting one 12-ply stack, 18" long, inboard on bottom side

4. Lead-lag resonance method changed from manual to accelerometer-DSO at SN6 


$\begin{array}{llll}\text { Material } & \text { Vendor PN } & \text { Mfr } & \text { Specifiication } \\ \text { Carbon } & \text { AF254-A534-150-35 } & \text { Aldila } & 150 / 35 \% \text { (Standard uni-tape) } \\ \text { Fiberglass } & \text { ZMG2000-S2-140-38 } & \text { Zoltek } & 140 / 35 \% \text { (S2 glass, 140 faw) } \\ \text { Foam, 1/8" } & 51 \mathrm{fx} & \text { Rohacell } 3 \times 48 \times 1 / 8 \text { inch, stiffener, } 4 \text { pieces per blade }\end{array}$

\begin{tabular}{|c|c|c|c|c|c|c|c|c|c|c|c|}
\hline 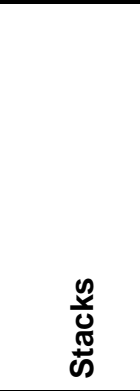 & 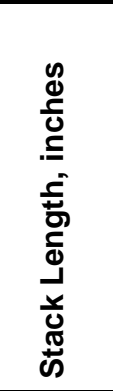 & 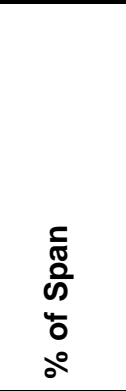 & 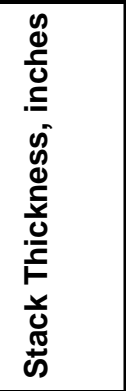 & 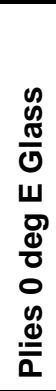 & 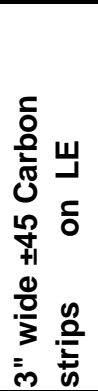 & 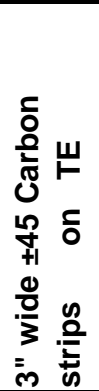 & 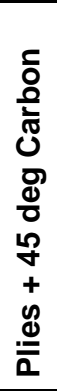 & 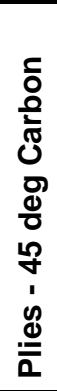 & 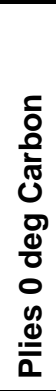 & 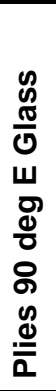 & 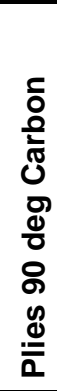 \\
\hline Outer & 225.5 & $100 \%$ & 0.060 & 4 & 4 & 4 & 4 & 4 & 0 & 0 & 0 \\
\hline Second & 111 & $49.2 \%$ & 0.060 & 4 & 0 & 0 & 4 & 4 & 0 & 0 & 0 \\
\hline Third & 67 & $29.7 \%$ & 0.060 & 4 & 0 & 0 & 4 & 4 & 0 & 0 & 0 \\
\hline Fourth & 43 & $19.1 \%$ & 0.060 & 4 & 0 & 0 & 4 & 4 & 0 & 0 & 0 \\
\hline Fifth & 18 & $8.0 \%$ & 0.060 & 4 & 0 & 0 & 4 & 4 & 0 & 0 & 0 \\
\hline \multicolumn{3}{|c|}{ Total thickness at root end: } & 0.300 & & & & & & & & \\
\hline
\end{tabular}

Table 3. Materials and Lamination Schedule

\subsection{Production Cost Model: Total Cost and Selling Price per Blade (Material, Time, Margin)}

Assuming that process development is amortized in the first year, we offer the following simple model for estimating selling price per blade, given:

- Total amount of material in the blade;

- Manufacturer's margin is $20 \%$ of (material + labor + direct overhead)

\begin{tabular}{|l|r|r|r|r|}
\hline Quantity & 50 & 1,000 & 10,000 & 10,000 \\
\hline Material & 36.9 & 42.0 & 43.3 & 54.9 \\
\hline Labor & 34.3 & 38.6 & 34.3 & 21.1 \\
\hline Direct Overhead & 1.5 & 2.0 & 5.7 & 7.2 \\
\hline QC O+P @ 20\% & 14.5 & 16.5 & 16.6 & 16.6 \\
\hline Process develop @ \$15K & 12.7 & 0.9 & 0.1 & 0.1 \\
\hline TOTAL & 100.0 & 100.0 & 100.0 & 100.0 \\
\hline
\end{tabular}

Table 4. Sell Price Components

\subsection{Estimated Volume Production Cost per Blade: Table 5; Figures 1-4}

Proceeding from the "Rules..." and models, above, and based on the limited experience of producing 13 blades, Quatro Composites (QC) estimates these volume manufacturing costs for the blade used in this project, as shown in Figs. 1 - 4.

At annual production volume of 10,000, per blade sell price, not including design and tooling amortization, for this $5.7 \mathrm{~m}$ long blade, ready to install, is about:

- $\$ 1,500$ for manufacture in Poway, CA, near San Diego

- $\$ 1,200$ for manufacture in Mexico 


\subsection{Conclusion}

We believe we have successfully demonstrated tooling for, and prototype production of, a $5.7 \mathrm{~m}$ long all-composite blade by the HCBMP process, which can probably successfully build any hollow blade up to $\sim 6-8 \mathrm{~m}$ long. A small, simple internal structure, such as the LEDS in the project blade, may be incorporated in the molding process; this remains to be proven. Figures A-D, pp 41-44, are the blade design, which remains the property of ESA.

We do not know whether the year 2004 \$US estimated selling prices of a finished, ready-to-fly blade of the design used in this project, at 10,000 annual production, is attractive and competitive:

- $\quad \$ 1,500$, for production in Poway, CA;

- $\quad \sim \$ 1,200$, for production in Mexico.

We recommend further investigation of this HCBMP process for small (probably $<6-8 \mathrm{~m}$ blade length), all-composite wind turbine blades. Many process variations should be tried. HCBMP requires a costly aluminum mold for heat transfer during brief cure cycle in airspring press.

We will continue flying the three sets of flyable blades produced under this project, all shortened by removing $\sim 1 \mathrm{~m}$ from the tip, reporting any data or observation to NREL and NWTC. These three sets were installed and operating at 15 May 05. At 15 Sept 05, all blades were in good operating condition.

Figures 7 - 26 are not discussed in the text, above. The captions adequately explain them.

\begin{tabular}{|c|c|c|c|}
\hline \multicolumn{2}{|l|}{ MATERIAL } & $\begin{array}{l}\text { \$ Per } \\
\text { Pound }\end{array}$ & $\begin{array}{l}\text { \$ Per } \\
\text { Blade }\end{array}$ \\
\hline \multicolumn{2}{|c|}{ Carbon prepreg } & 9.50 & 313.50 \\
\hline \multicolumn{2}{|c|}{ Glass prepreg } & 8.50 & 136.00 \\
\hline \multicolumn{2}{|l|}{ Bladder } & & 50.00 \\
\hline \multirow[t]{5}{*}{ LEDS } & cleaners & & 2.00 \\
\hline & shot & & 20.00 \\
\hline & epoxy & & 24.00 \\
\hline & fabric & & 6.00 \\
\hline & misc matls, tooling & & 0.50 \\
\hline \multirow[t]{4}{*}{ Root Box fill } & dam & & 1.00 \\
\hline & epoxy & & 35.00 \\
\hline & Al pellets & & 7.50 \\
\hline & misc matls, tooling & & 2.50 \\
\hline \multicolumn{2}{|c|}{ Lifting pad eye } & & 2.00 \\
\hline \multicolumn{2}{|c|}{ SS washers (set of 6) } & & 4.00 \\
\hline \multicolumn{4}{|c|}{ Structural } \\
\hline \multirow[t]{2}{*}{ adhesive } & SS fittings & & 2.00 \\
\hline & LEDS install & & 5.00 \\
\hline \multicolumn{2}{|c|}{ Supplies (trim, deflash) } & & 2.00 \\
\hline \multirow[t]{4}{*}{ Paint } & primer & & 8.00 \\
\hline & paint & & 15.00 \\
\hline & thinner & & 3.00 \\
\hline & misc matls, tooling & & 3.00 \\
\hline \multicolumn{2}{|c|}{ Tip balancing shot + UR resin } & & 4.00 \\
\hline \multicolumn{2}{|c|}{ SUBTOTAL MATERIAL } & & 646.00 \\
\hline
\end{tabular}




\begin{tabular}{|c|c|c|c|c|}
\hline \multicolumn{2}{|l|}{ LABOR } & $\begin{array}{c}\text { Person- } \\
\text { Hours }\end{array}$ & $\begin{array}{l}\text { \$ per hr } \\
\text { Burdened } \\
\text { Rate }\end{array}$ & $\begin{array}{c}\text { Cost } \\
\text { per } \\
\text { Blade } \\
\$\end{array}$ \\
\hline \multirow[t]{3}{*}{ LEDS } & Shot wash, dry, weigh & 0.5 & 12.00 & 6.00 \\
\hline & Molding part & 1 & 12.00 & 12.00 \\
\hline & Cleanup and prep part & 0.5 & 12.00 & 6.00 \\
\hline \multicolumn{2}{|c|}{ Sheeting/slitting } & 1.5 & 12.00 & 18.00 \\
\hline \multicolumn{2}{|c|}{ Stacking } & 7 & 12.00 & 84.00 \\
\hline \multicolumn{2}{|c|}{ Cutting } & 3 & 12.00 & 36.00 \\
\hline \multicolumn{2}{|c|}{ Consolidate prepreg stacks } & 2 & 12.00 & 24.00 \\
\hline \multicolumn{2}{|c|}{ Prep mold and press } & 1 & 12.00 & 12.00 \\
\hline \multicolumn{2}{|c|}{ Load mold } & 3.5 & 12.00 & 42.00 \\
\hline \multicolumn{2}{|c|}{ Cure and demold } & 3 & 12.00 & 36.00 \\
\hline \multicolumn{2}{|c|}{ Deflash } & 1 & 12.00 & 12.00 \\
\hline \multicolumn{2}{|c|}{ Repair surface flaws } & 1 & 12.00 & 12.00 \\
\hline \multicolumn{2}{|c|}{ Trim root box to length } & 0.5 & 12.00 & 6.00 \\
\hline \multicolumn{2}{|c|}{ Install LEDS; assume adhesive } & 1 & 12.00 & 12.00 \\
\hline \multicolumn{2}{|c|}{ Drill root box } & 0.5 & 12.00 & 6.00 \\
\hline \multicolumn{2}{|c|}{ Fill root box } & 2 & 12.00 & 24.00 \\
\hline \multicolumn{5}{|c|}{ Install lifting pad eye, washers; } \\
\hline \multicolumn{2}{|c|}{ Prep for paint; booth move in / out } & 4 & 12.00 & 48.00 \\
\hline \multicolumn{2}{|c|}{ Prime and paint and cleanup } & 3 & 30.00 & 90.00 \\
\hline \multicolumn{2}{|c|}{ Tip balancing } & 1 & 12.00 & 12.00 \\
\hline \multicolumn{2}{|c|}{ Properties measure, data record } & 0.5 & 12.00 & 6.00 \\
\hline \multicolumn{2}{|c|}{ Documentation } & 0.04 & 30.00 & 1.20 \\
\hline \multicolumn{2}{|c|}{ SUBTOTAL LABOR } & & & 511.20 \\
\hline \multicolumn{5}{|c|}{ DIRECT OVERHEAD } \\
\hline \multicolumn{2}{|c|}{ Electric energy } & & & 5.00 \\
\hline \multicolumn{2}{|c|}{ Misc supplies:acetone, wipes, etc. } & & & 5.00 \\
\hline \multicolumn{2}{|c|}{ Janitorial } & & & 5.00 \\
\hline \multicolumn{2}{|c|}{ Tool wear } & & & 5.00 \\
\hline \multicolumn{2}{|c|}{ Paint booth rental } & & & 15.00 \\
\hline Tooling & & & & 50.00 \\
\hline SUBTO & СT OHD & & & 85.00 \\
\hline SUBTO & JFACTURING DIRECT COST & & & $1,242.20$ \\
\hline QC Ove & fit @ 20\% & & & 248.44 \\
\hline BLADE & & & & $1,490.64$ \\
\hline
\end{tabular}

Table 5. Estimated Sell Price Detail: Build 10,000 per year in Poway, CA, at QC plant; Sept 04 costs; carbon prepreg cost has increased $\sim 15 \%$ by Apr 05. 


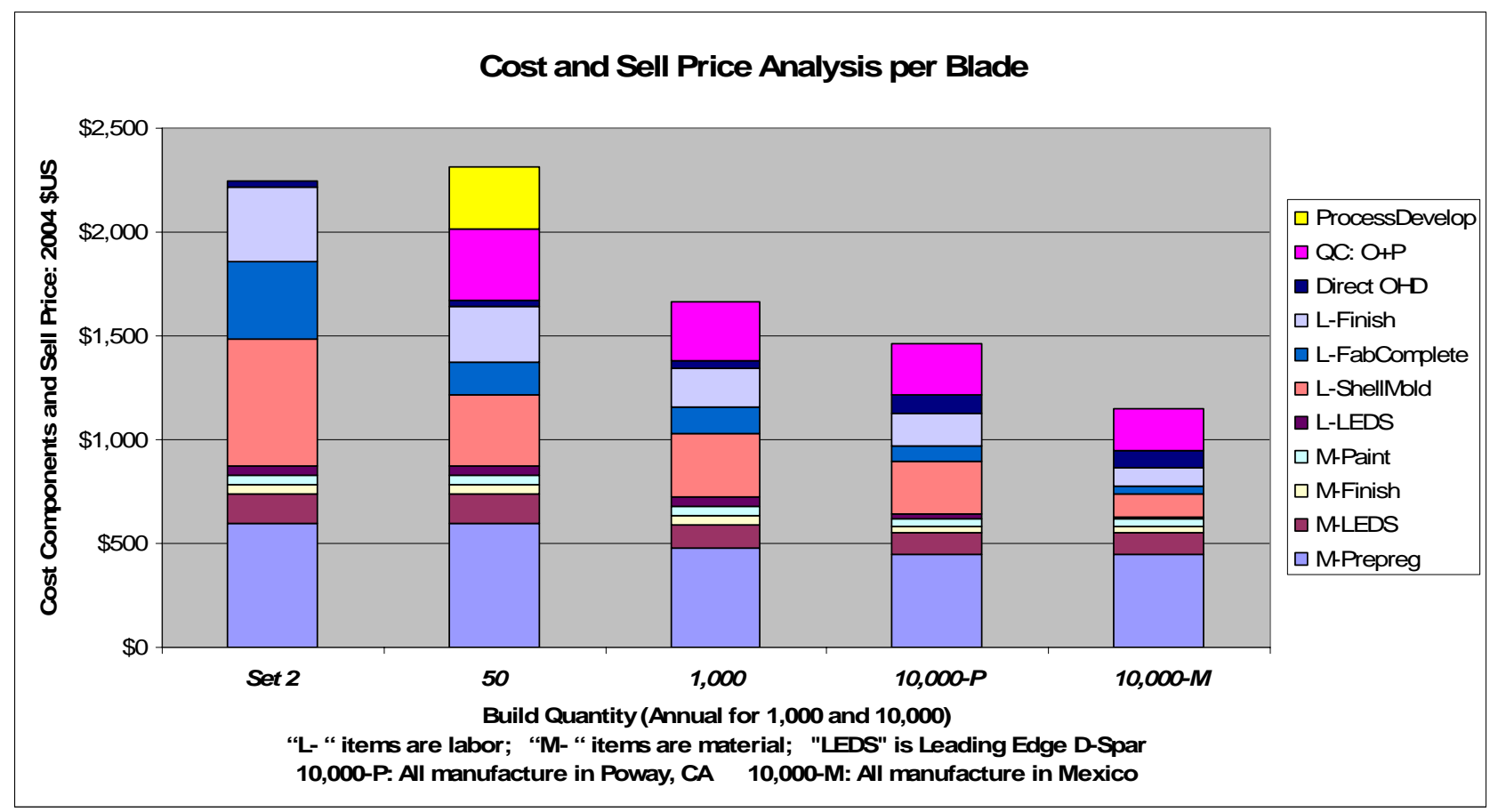

Figure 1. Estimated Sell Price per Blade, annual quantity 1,000 and 10,000 , based on component cost analysis; Sept 04 costs; carbon prepreg cost has increased 15\% by Apr 05.

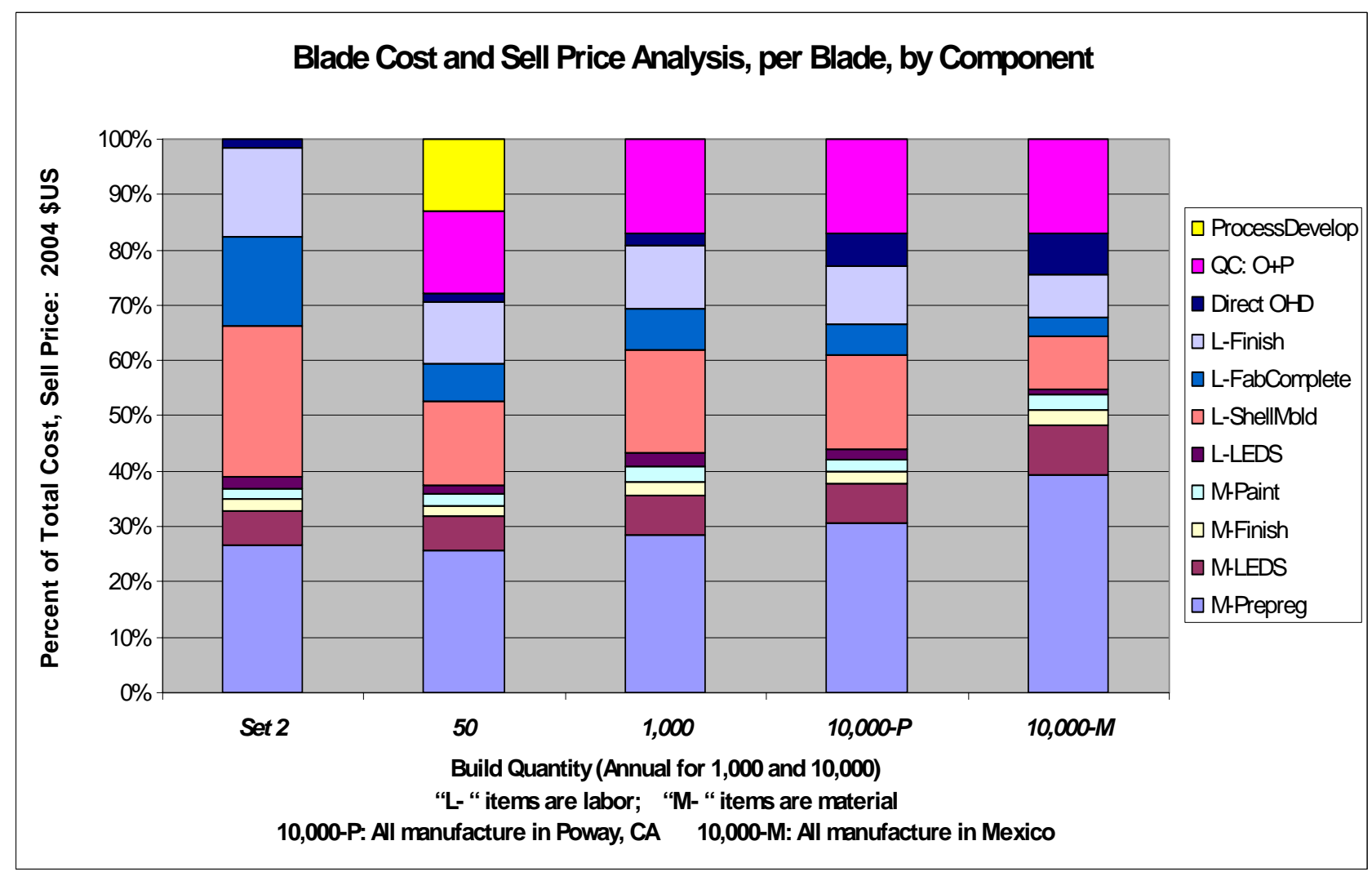

Figure 2. Estimated Sell Price per Blade, annual quantity 1,000 and 10,000 , based on component cost analysis; Sept 04 costs; carbon prepreg cost has increased $\sim 15 \%$ by Apr 05 . 


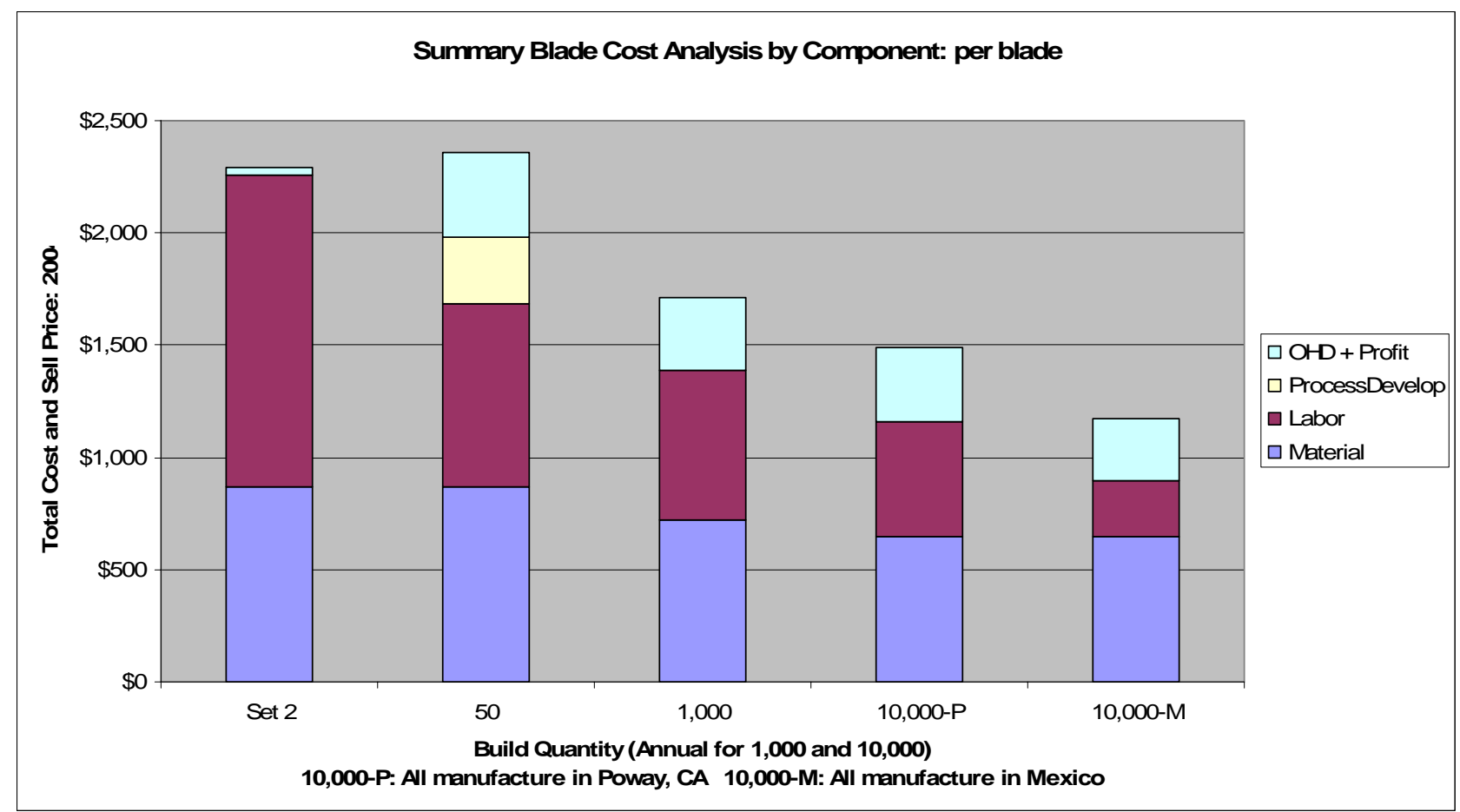

Figure 3. Estimated Sell Price per Blade, annual quantity 1,000 and 10,000. Sept 04 costs; carbon prepreg cost has increased $\sim 15 \%$ by Apr 05 .

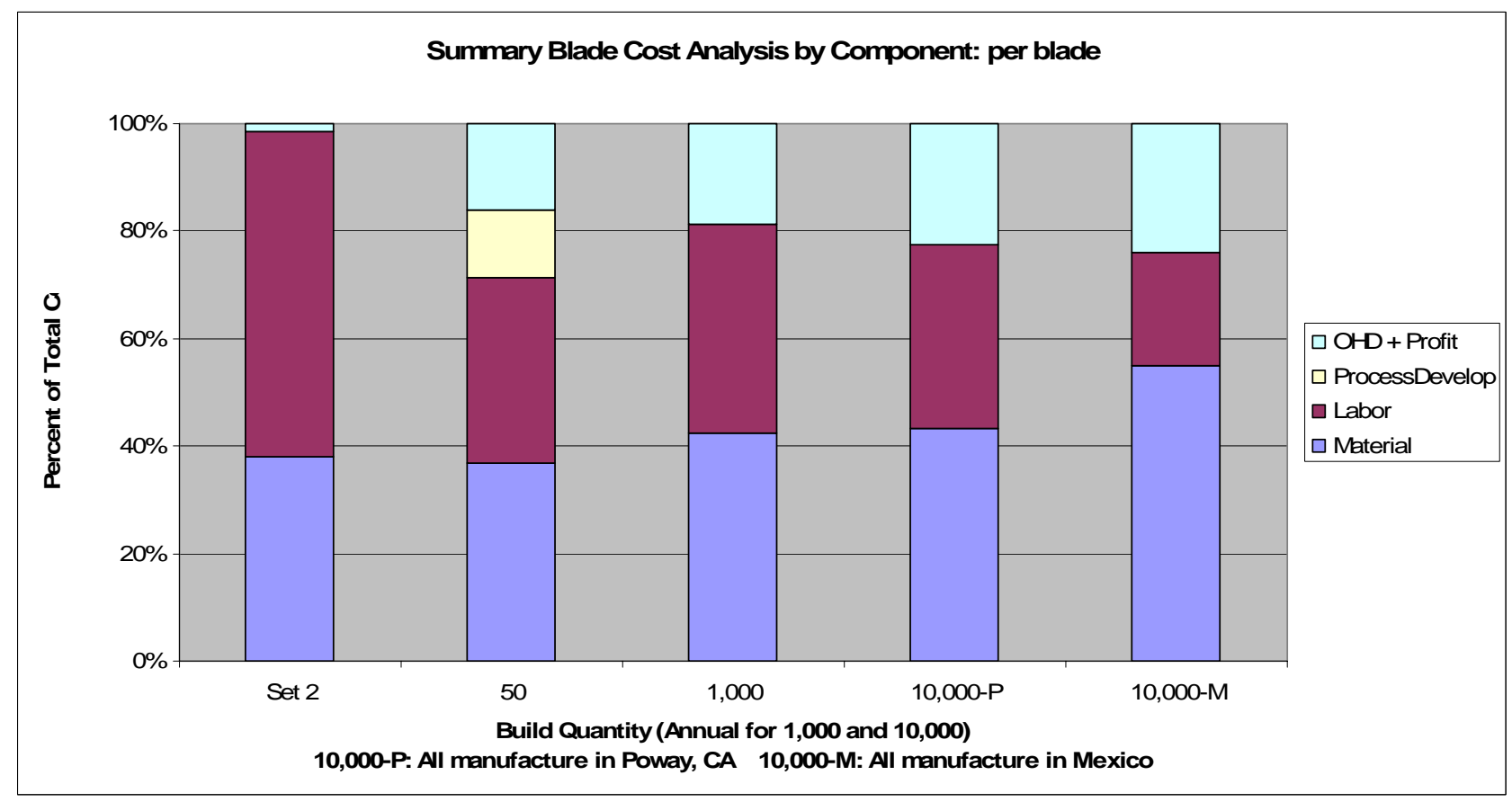

Figure 4. Estimated Sell Price per Blade, annual quantity 1,000 and 10,000. Sept 04 costs; carbon prepreg cost has increased $\sim 15 \%$ by Apr 05 . 


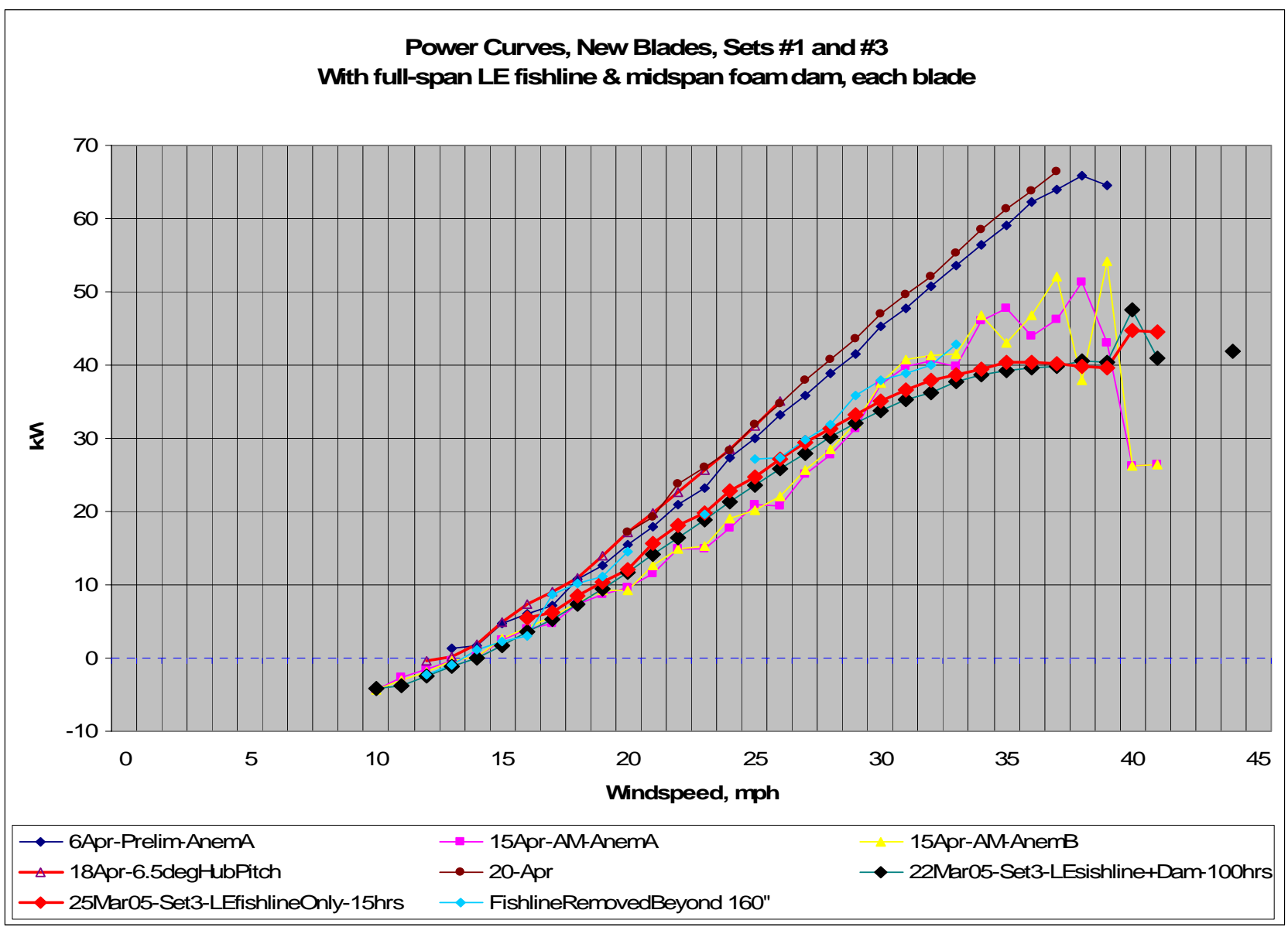

Figure 5. Power curves for several configurations of the three sets of full-length flyable blades built in this project, from data on the instrumented site B1 machine. Upper curves are unmodified blade; lower curves are modified for attempted stall regulation, with LE stall strip and spanwise flow dam. 


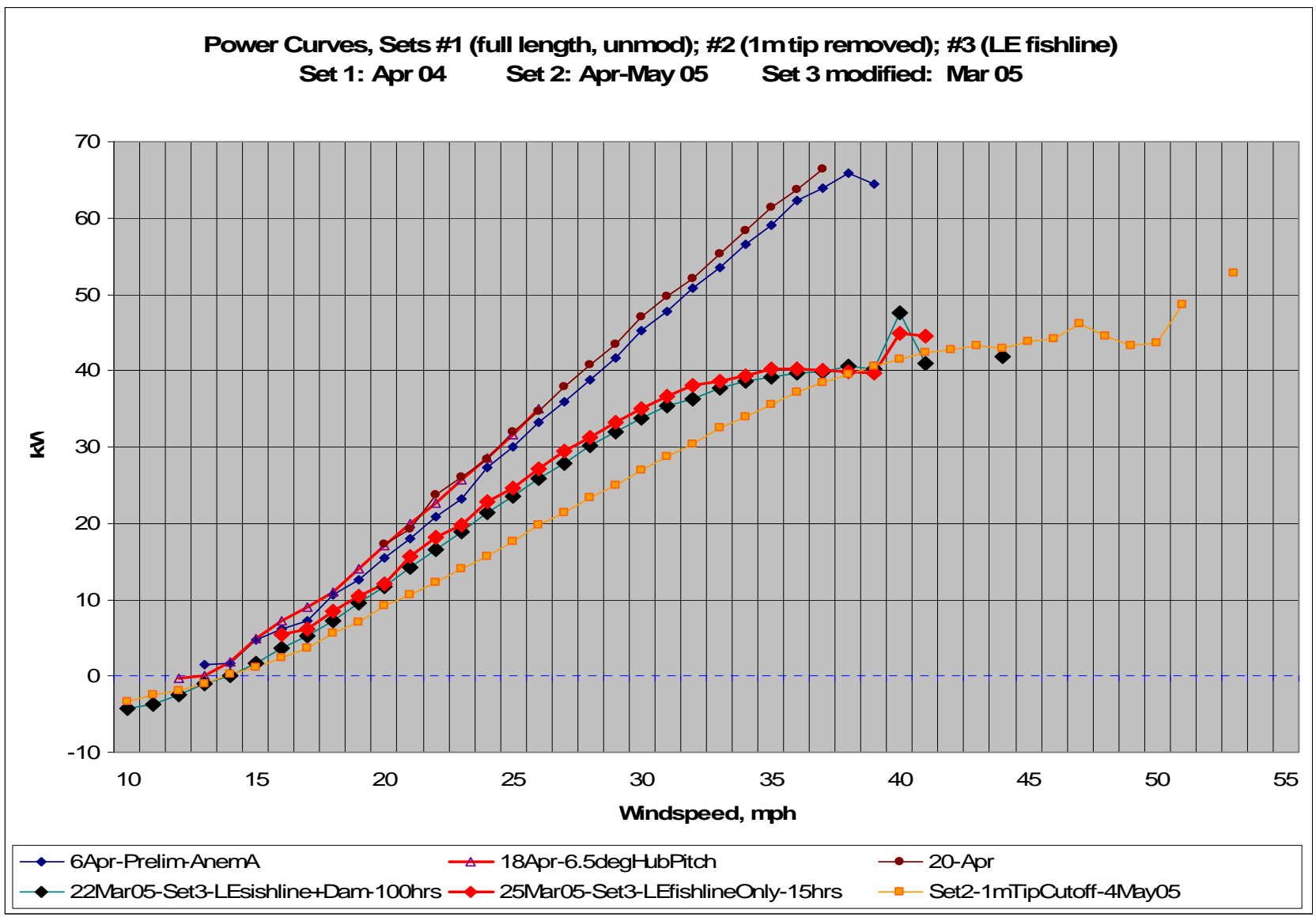

Figure 6. Measured power curves, B1 instrumented test site. Same as Figure 5 except lower curve is set \#2 shortened by removing $1 \mathrm{~m}$ from each tip. 


\begin{tabular}{|c|c|c|c|c|c|c|}
\hline \multirow{2}{*}{$\begin{array}{c}\text { Task } \\
\text { Number }\end{array}$} & \multirow{2}{*}{ Task Description } & \multicolumn{4}{|c|}{ Task Completion Date } & \multirow{2}{*}{ Progress Notes } \\
\hline & & $\begin{array}{l}\text { Original } \\
\text { Planned }\end{array}$ & $\begin{array}{l}\text { Revised } \\
\text { Planned }\end{array}$ & Actual & $\begin{array}{l}\text { Percent } \\
\text { Complete }\end{array}$ & \\
\hline 1 & $\begin{array}{l}\text { Airspring Press design, } \\
\text { fabricate, wire, test }\end{array}$ & 8 Jan 04 & & 10 Mar 04 & $100 \%$ & $\begin{array}{l}\text { Complete; Works } \\
\text { well }\end{array}$ \\
\hline 2 & $\begin{array}{c}\text { Blade design in SolidWorks } \\
\text { by Salter \& Associates }\end{array}$ & $20 \mathrm{Dec} 03$ & & 15 Feb 03 & $100 \%$ & Complete \\
\hline 3 & $\begin{array}{c}\text { Tool path files for } \mathrm{NC} \text { mill to } \\
\text { machine mold sections }\end{array}$ & $23 \operatorname{Dec} 03$ & 19 Jan 04 & 31 Jan 04 & $100 \%$ & $\begin{array}{l}\text { Complete; } \$ 2,000 \\
\text { added cost for } \\
\text { software consultant }\end{array}$ \\
\hline 4 & $\begin{array}{c}\text { NC machine mold sections, } \\
\text { rear }\end{array}$ & 8 Jan 04 & 20 Jan 04 & 20 Jan 04 & $100 \%$ & Complete \\
\hline 5 & Approve mold design & $16 \mathrm{Dec} 03$ & 9 Feb 04 & 12 Feb 04 & $100 \%$ & Complete \\
\hline 6 & $\begin{array}{c}\text { NC machine mold sections, } \\
\text { front }\end{array}$ & 8 Jan 04 & 20 Feb 04 & 25 Feb 04 & $100 \%$ & Complete \\
\hline 7 & $\begin{array}{l}\text { Sand, polish, assemble, } \\
\text { approve, condition mold }\end{array}$ & 16 Jan 04 & 2 Mar 04 & 5 Mar 04 & $100 \%$ & Complete \\
\hline 8 & $\begin{array}{l}\text { First article blade for } \\
\text { properties test }\end{array}$ & 21 Jan 04 & 5 Mar 04 & 3 Mar 04 & $100 \%$ & Complete \\
\hline 9 & $\begin{array}{l}\text { Properties test; revise lam } \\
\text { schedule; make second } \\
\text { article blade for test }\end{array}$ & 28 Jan 04 & 10 Mar 04 & 5 Mar 04 & $100 \%$ & Complete \\
\hline 10 & QC delivers blade set \#1 & 6 Feb 04 & 23 Mar 04 & 23 Mar 04 & $100 \%$ & Complete \\
\hline 11 & $\begin{array}{l}\text { Blade set \#1 installed at } \\
\text { Palm Springs site }\end{array}$ & 1 Apr 04 & & 5 Apr 04 & $100 \%$ & Complete \\
\hline 12 & $\begin{array}{l}\text { Set \#1 power curve and } \\
\text { videotape operation from } \\
\text { ground and hub }\end{array}$ & & & 21 Apr 04 & $100 \%$ & Complete \\
\hline 13 & $\begin{array}{c}\text { Prepare for design review } \\
\text { and project status meeting } \\
\text { at NWTC, 3-4 May }\end{array}$ & & & 31 Apr 04 & $100 \%$ & $\begin{array}{l}\text { Complete: Ed Salter } \\
\text { represented project } \\
\text { at NWTC, 3-4 May }\end{array}$ \\
\hline 13 & $\begin{array}{l}\text { AASI in-kind contribution: } \\
\text { project mgmt; test site } \\
\text { preparation and operation }\end{array}$ & 30 Oct 04 & & 30 Apr 04 & $100 \%$ & $\begin{array}{l}\text { Complete: } 536 \\
\text { hours completed at } \\
30 \mathrm{Apr} 04:\end{array}$ \\
\hline 14 & $\begin{array}{c}\text { AASI cash cost share: } \\
\text { equipment, supplies, travel }\end{array}$ & 30 Oct 04 & & 30 Apr 04 & $100 \%$ & Complete: $>\$ 5,000$ \\
\hline 15 & QC completes set \#2 & 10 Jun 04 & 15 Sept 04 & 18 Sep 04 & $100 \%$ & Complete \\
\hline 16 & $\begin{array}{c}\text { Set \#2 replaces set \#1 at } \\
\text { Palm Springs test site, for } \\
\text { testing }\end{array}$ & $3 \mathrm{Jul} 04$ & 20 Sept 04 & 20 Sep 04 & $100 \%$ & Complete \\
\hline 17 & $\begin{array}{l}\text { QC volume mfg cost } \\
\text { estimates }\end{array}$ & 8 Oct 04 & 15 Oct 04 & 20 Oct 04 & $100 \%$ & $\begin{array}{c}\text { Complete; subject to } \\
\text { revision }\end{array}$ \\
\hline 18 & $\begin{array}{c}\text { Set \#3 replaces failed set } \\
\# 2 \text { at Palm Springs test site }\end{array}$ & none & Dec 04 & Jan 05 & $100 \%$ & $\begin{array}{l}\text { Power curve test } \\
\text { began } 26 \text { Jan } 05\end{array}$ \\
\hline 19 & Final report to DOE & 30 Oct 04 & 30 Jun 05 & & & On schedule \\
\hline
\end{tabular}




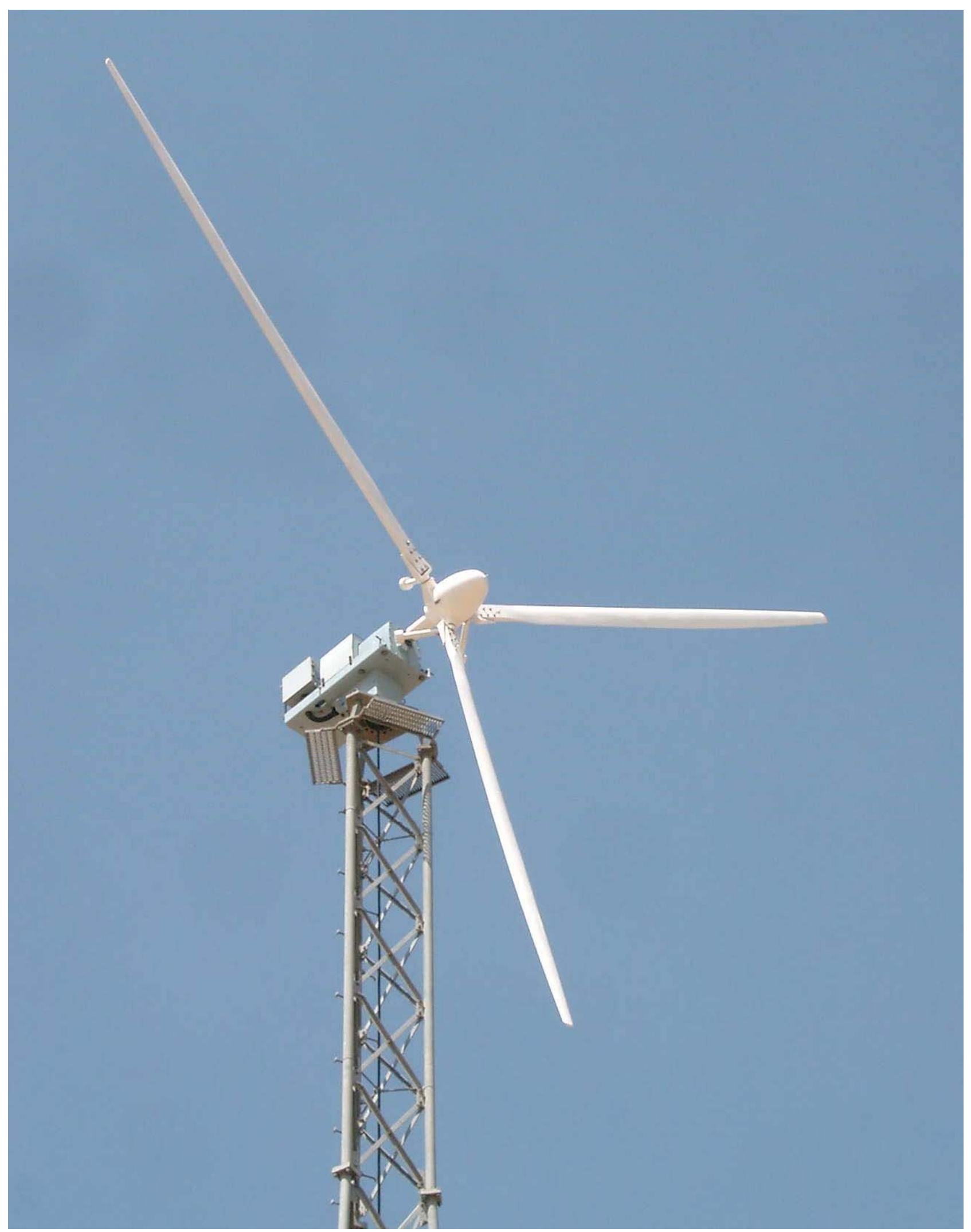

Figure 7. Instrumented test machine, BI site, AASI windplant, Palm Springs, CA 


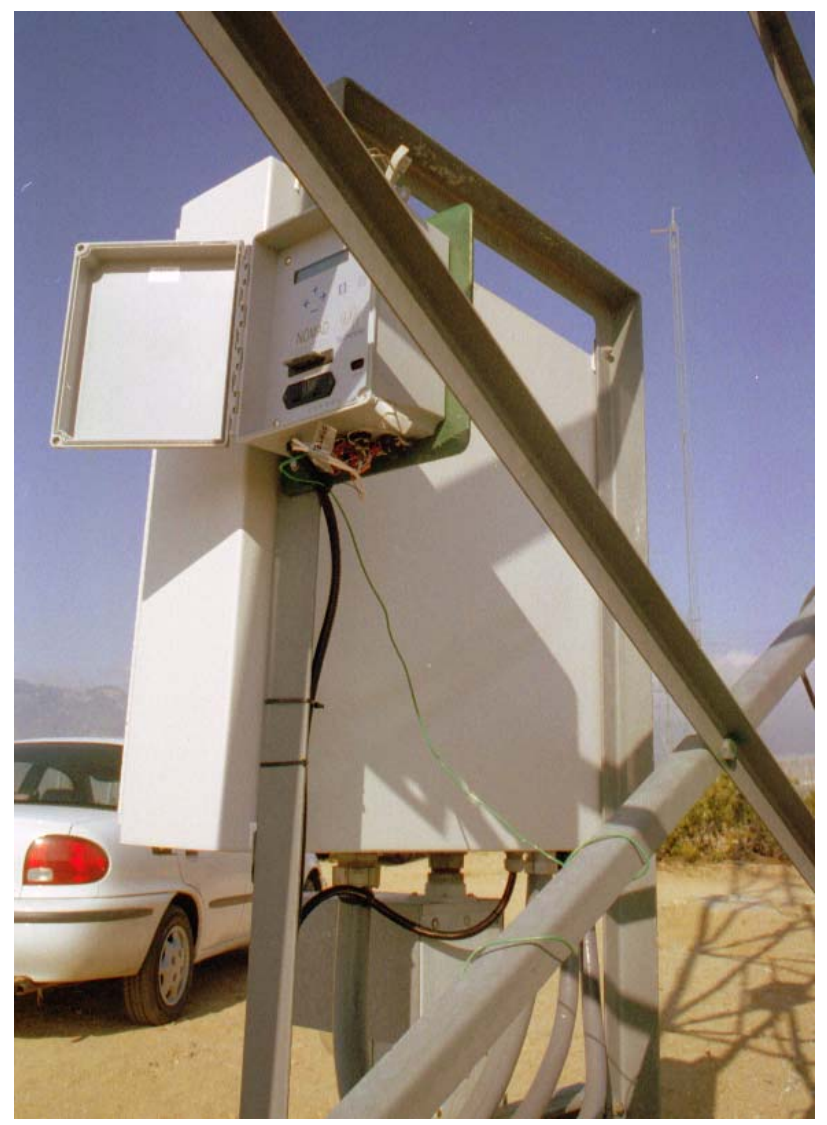

Figure 8. NOMAD datalogger on instrumented test machine, B1 site. Met tower in background.

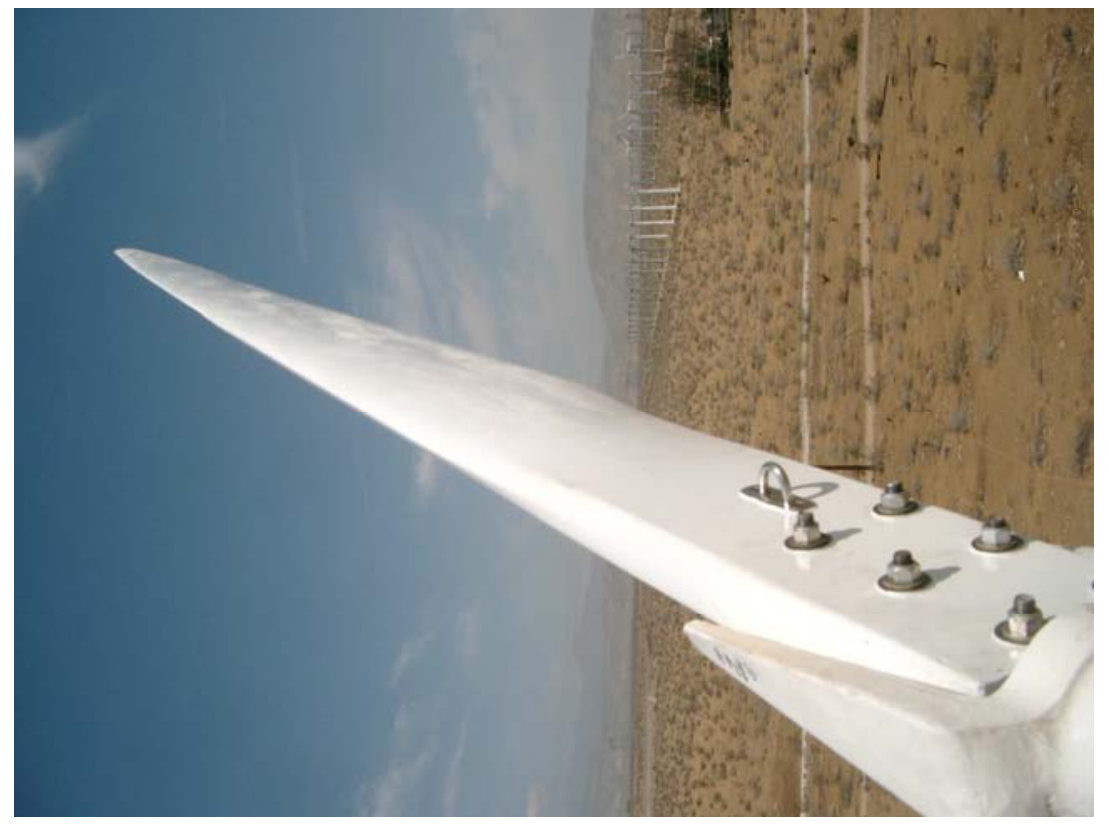

Figure 9. Set \#1 installed on B1 test machine, AASI windplant, Palm Springs, CA. 6 Apr 04. 


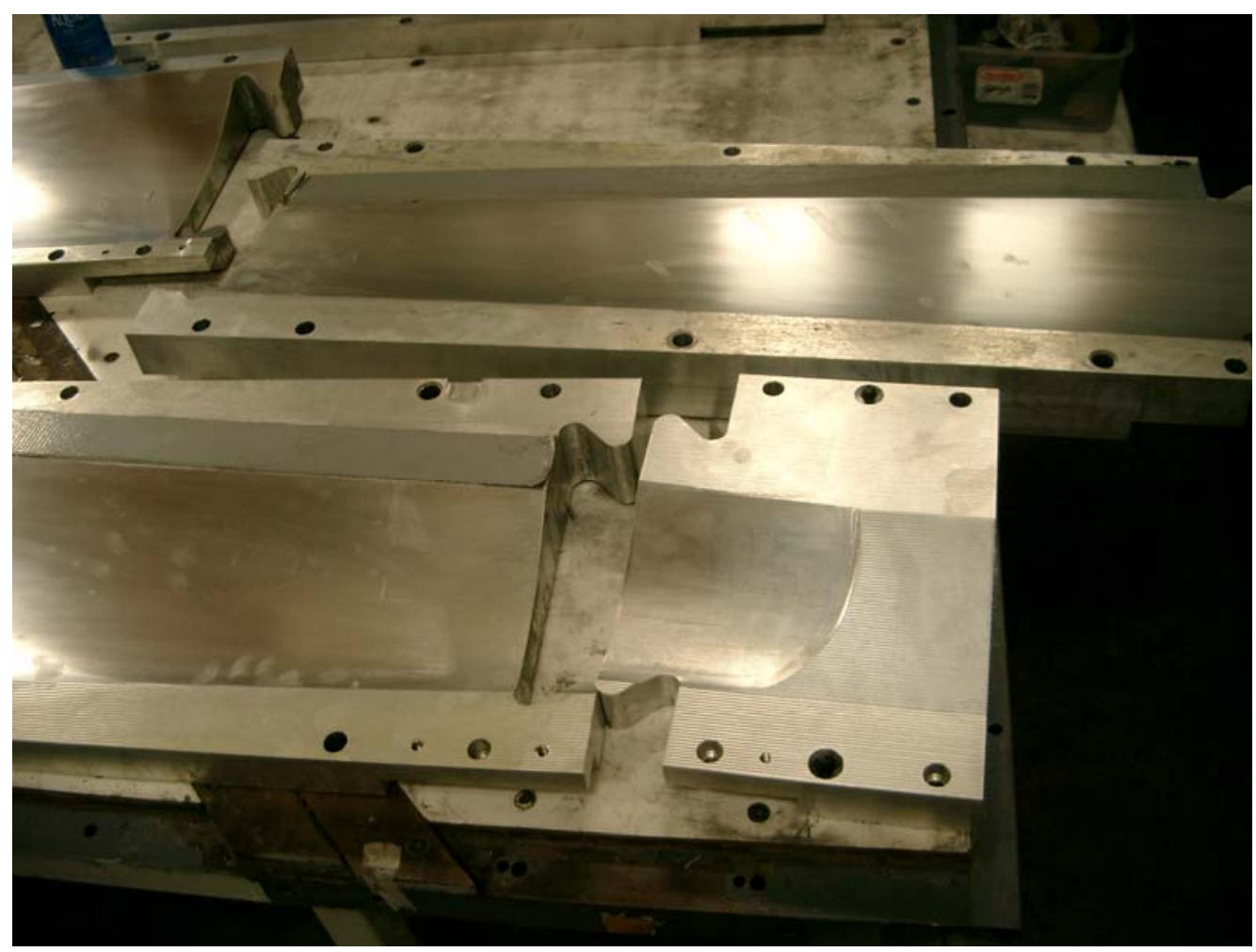

Figure 10. CNC-machined and polished aluminum mold segments, ready for assembly. Note dovetail joints. 30 Jan 04, Quatro Composites (QC), Poway, CA.

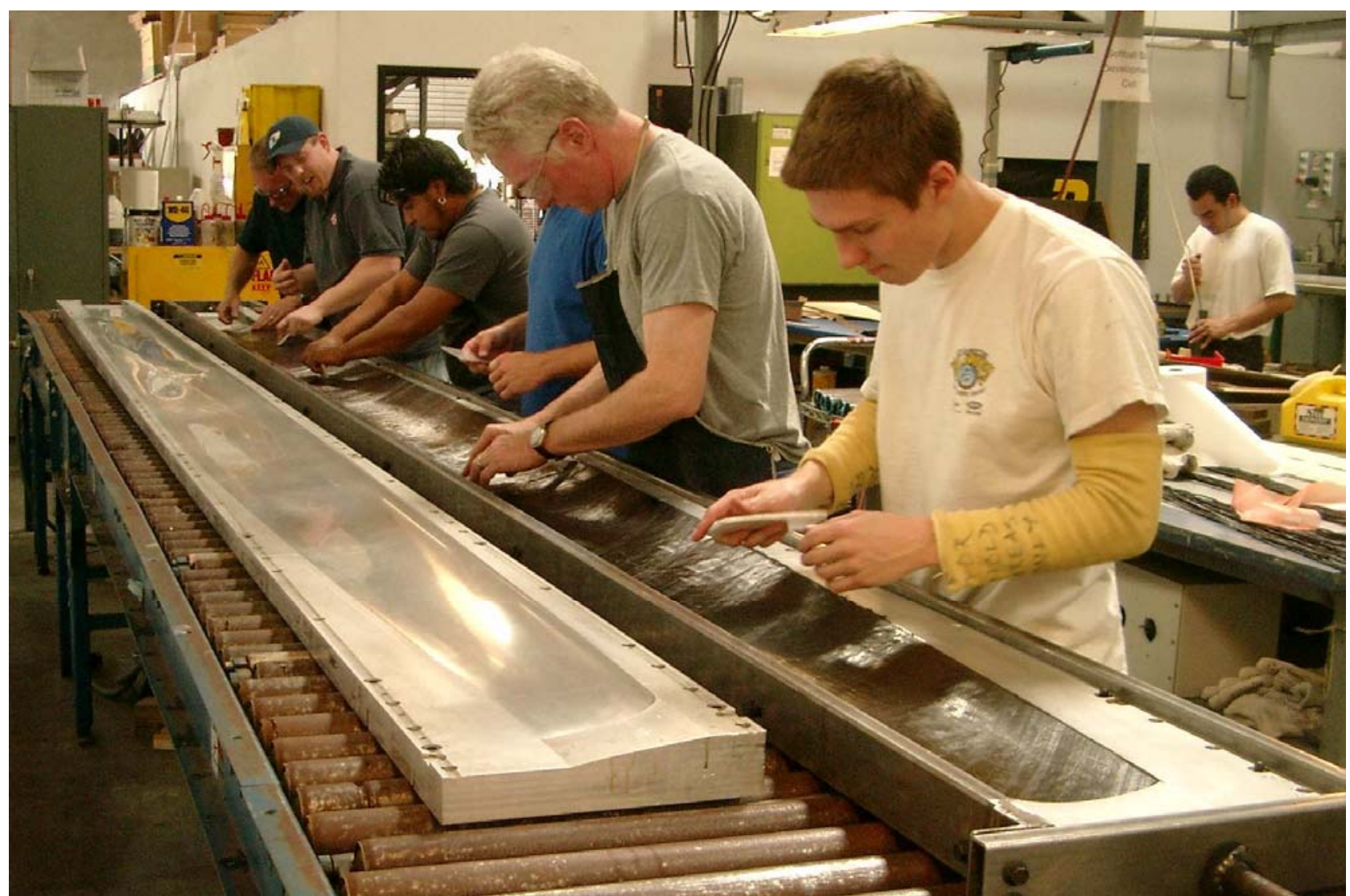

Figure 11. Prepreg layup in heated aluminum mold. 


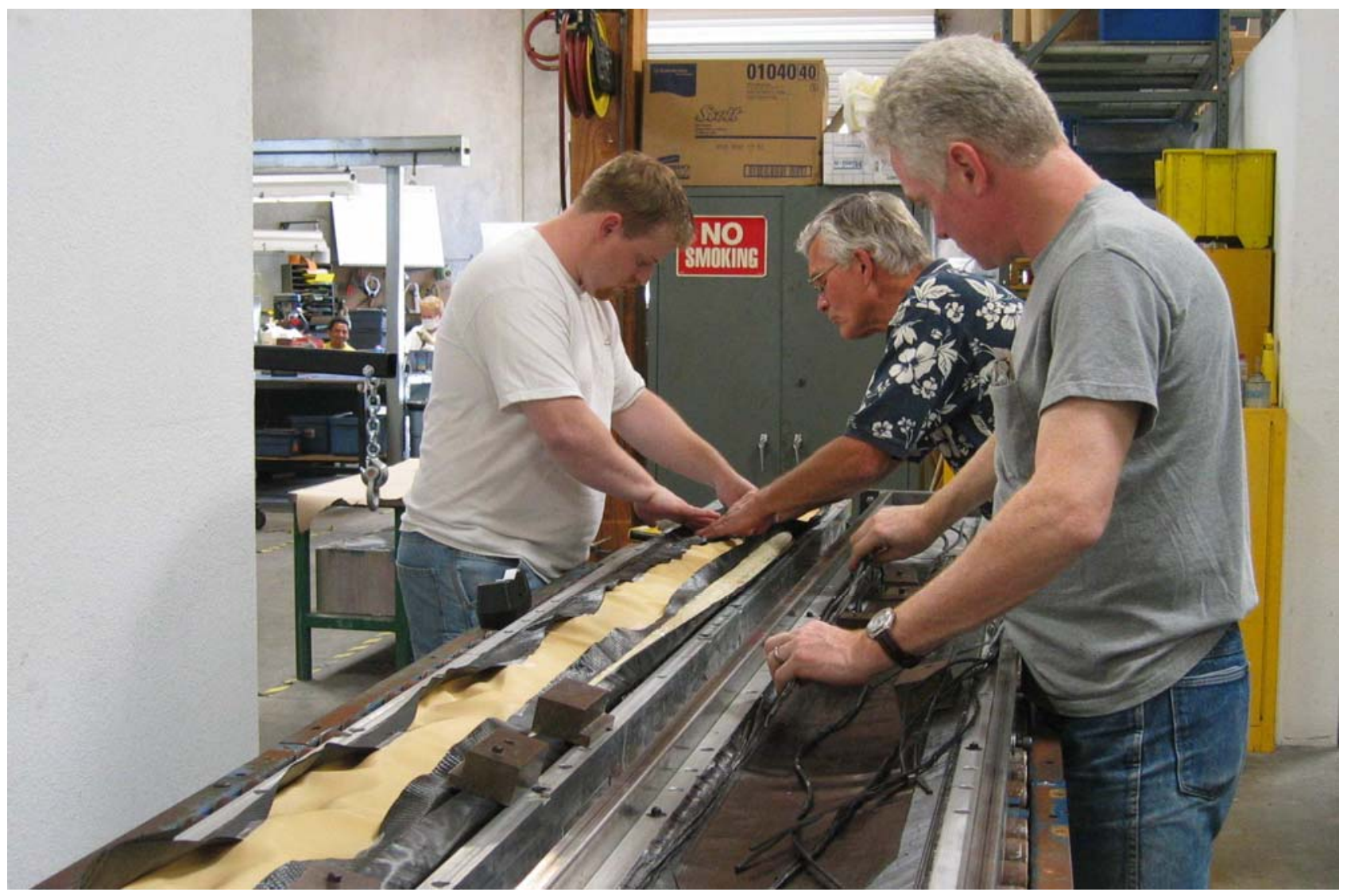

Figure 12. Bladder installation

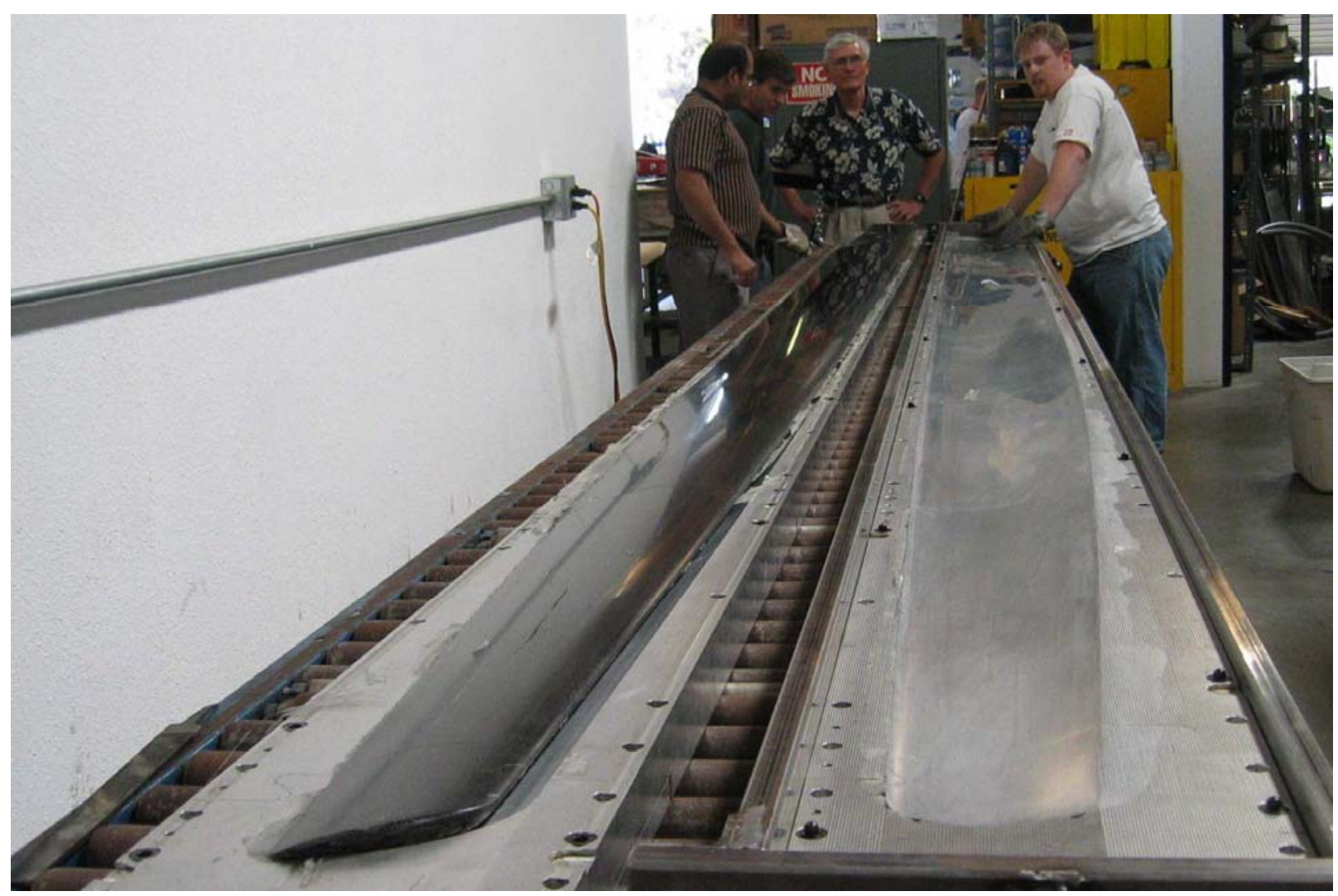

Figure 13. Demolding finished HCBMP blade at QC, Poway, CA. 


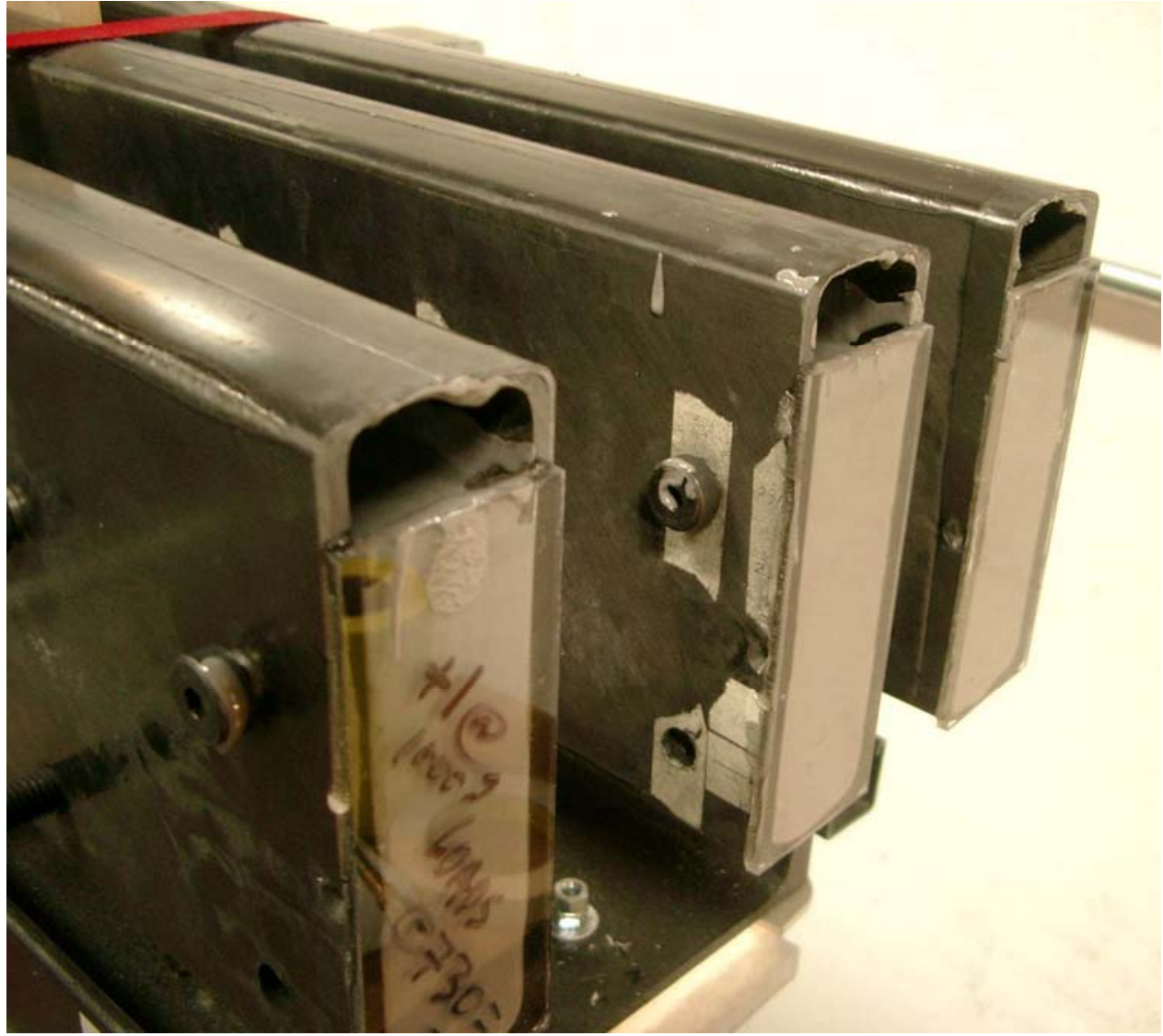

Figure 14. Root boxes filled with aluminum-filled epoxy mass casting, before tooling removal. 4-stage process avoids exotherm. Root box drilled before pour. Release-coated bolts make holes.

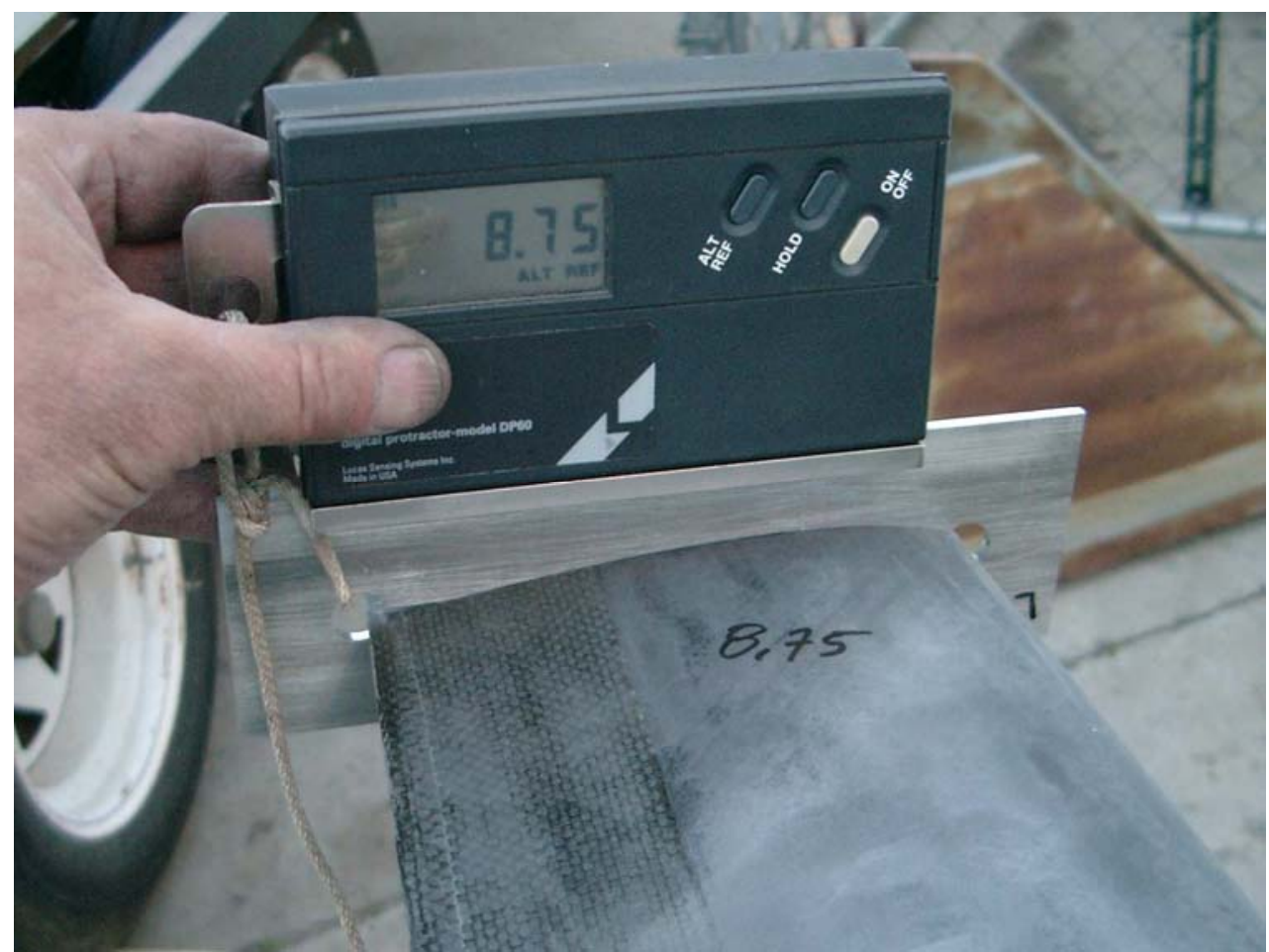

Figure 15. Tip twist angle inspection, with template. Nominal is $8.00 \mathrm{deg}$. Ref to root box. 


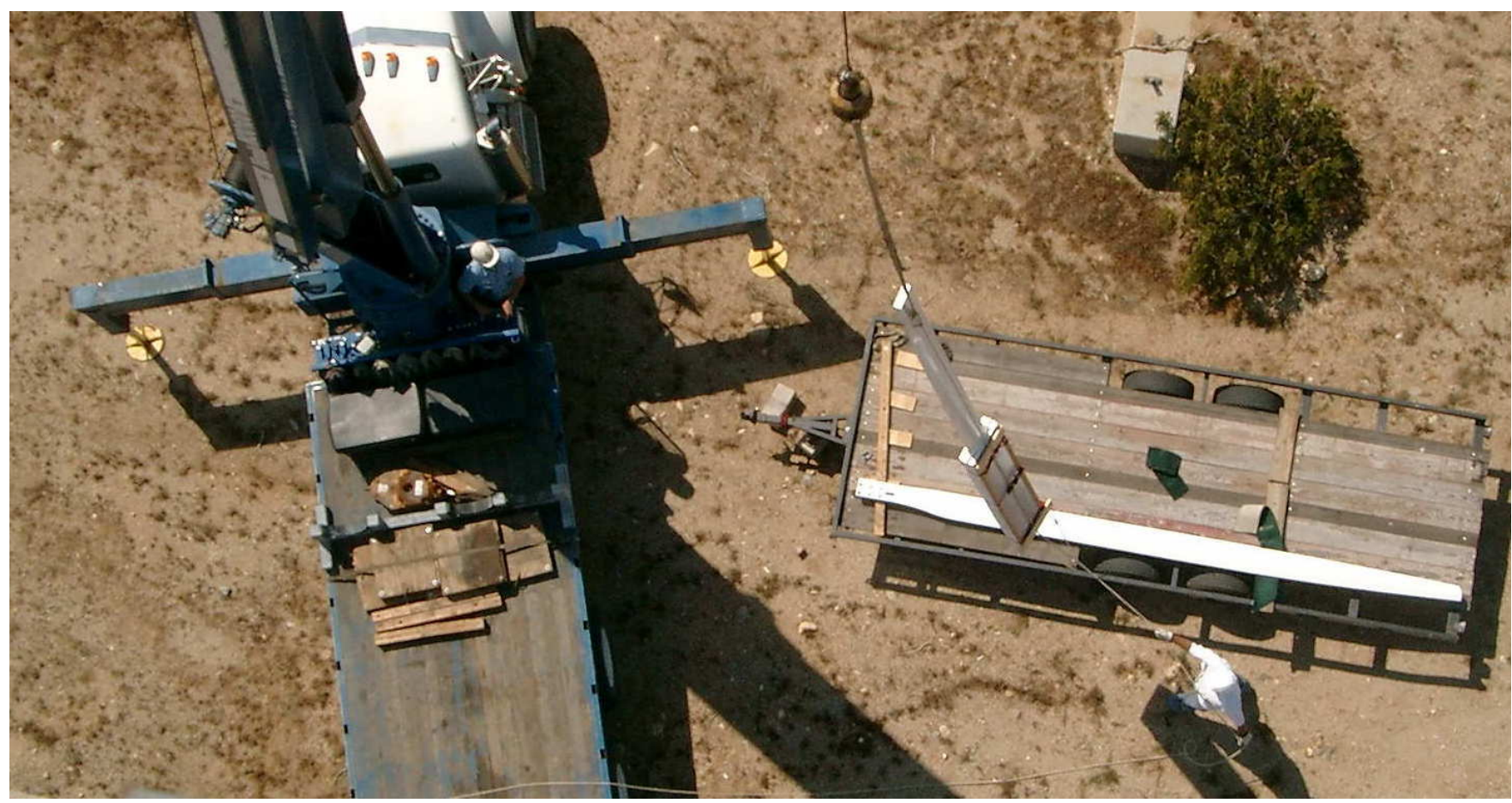

Figure 16. Installing set \#1 on B1 test machine, AASI windplant, Palm Springs, CA., 5 April 04. Note protective sleeve over outboard half of second blade, ascending. Third blade is on trailer.

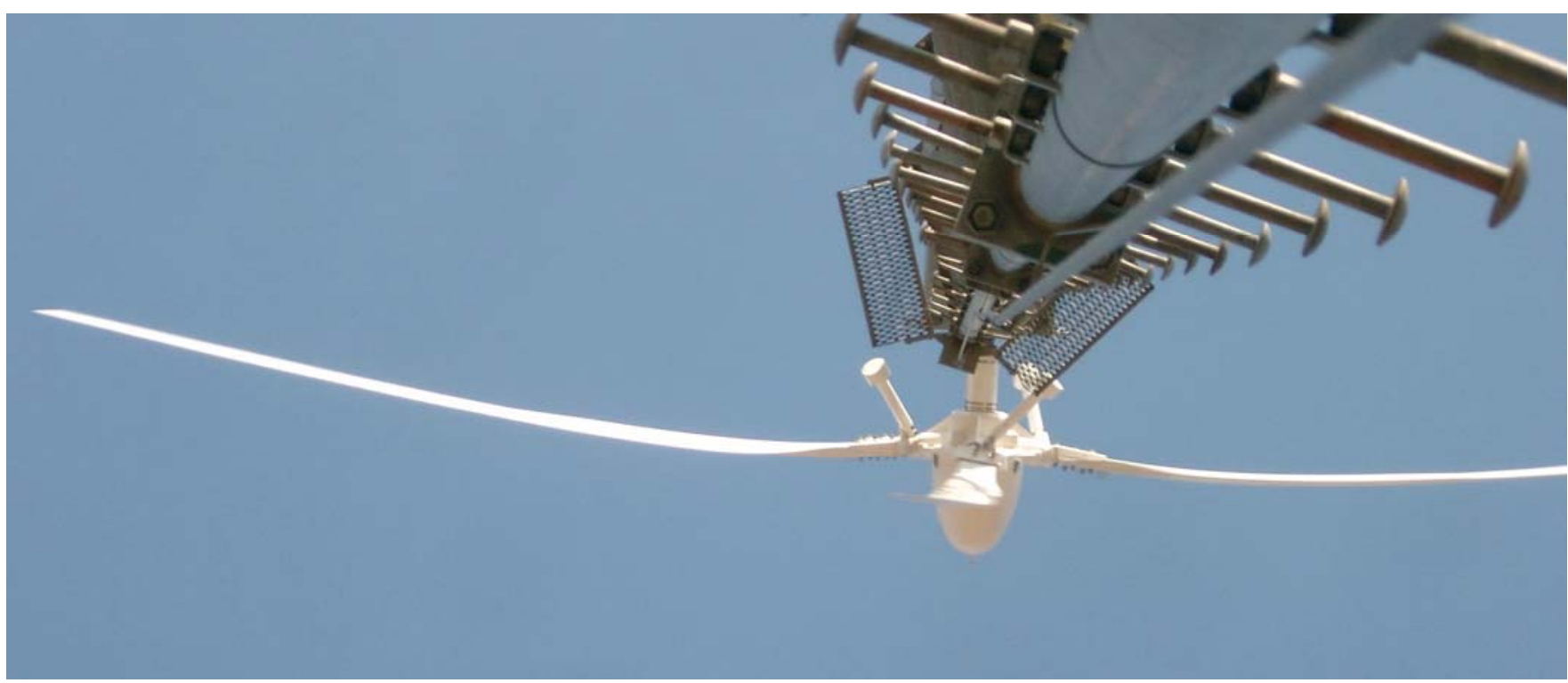

Figure 17. Set \#1 tower clearance with turbine upwind of tower, on-line, at 20-30 mph windspeed 


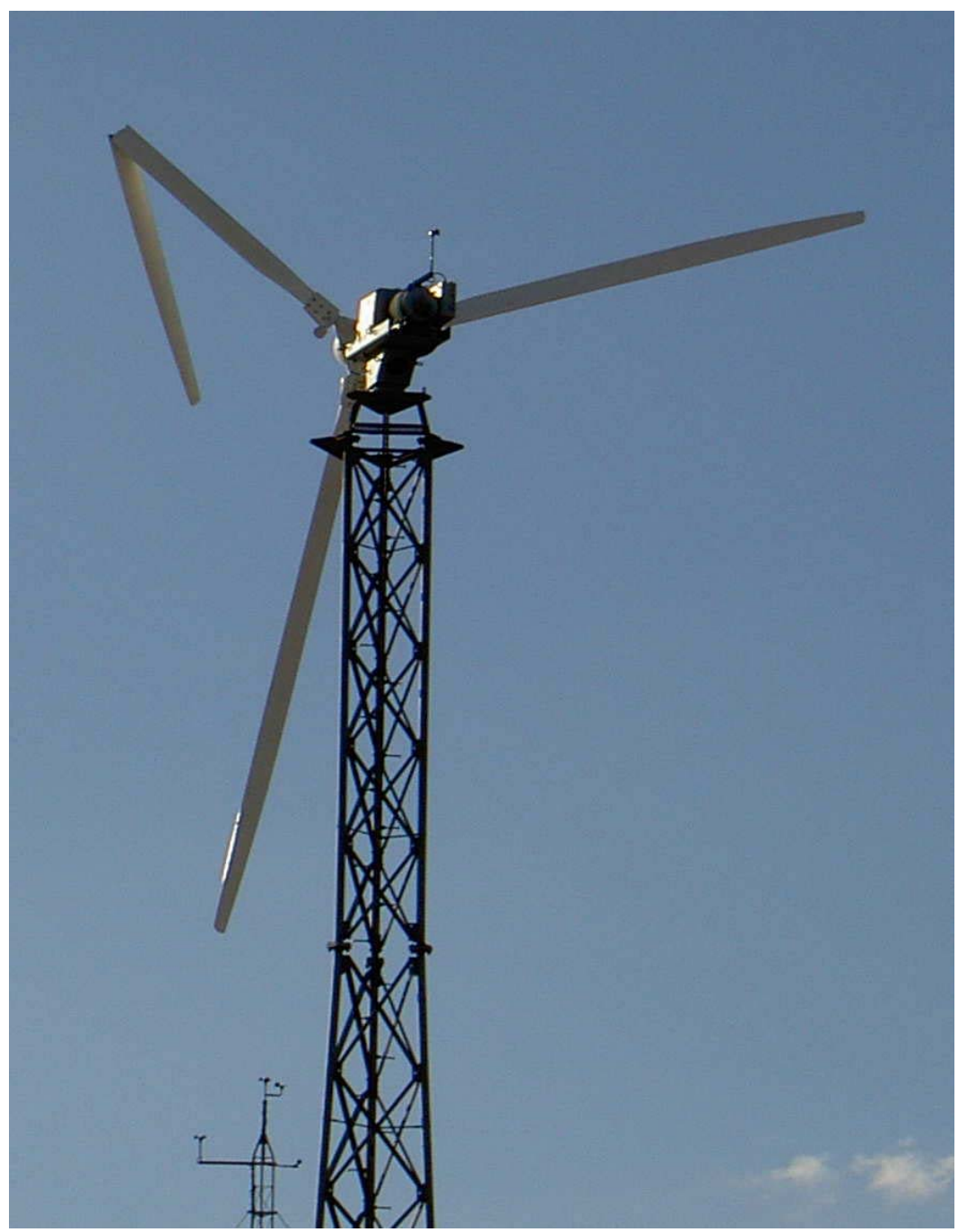

Figure 18. Nov 04. Broken Set \#2 blade on B1 test site, AASI Palm Springs windplant

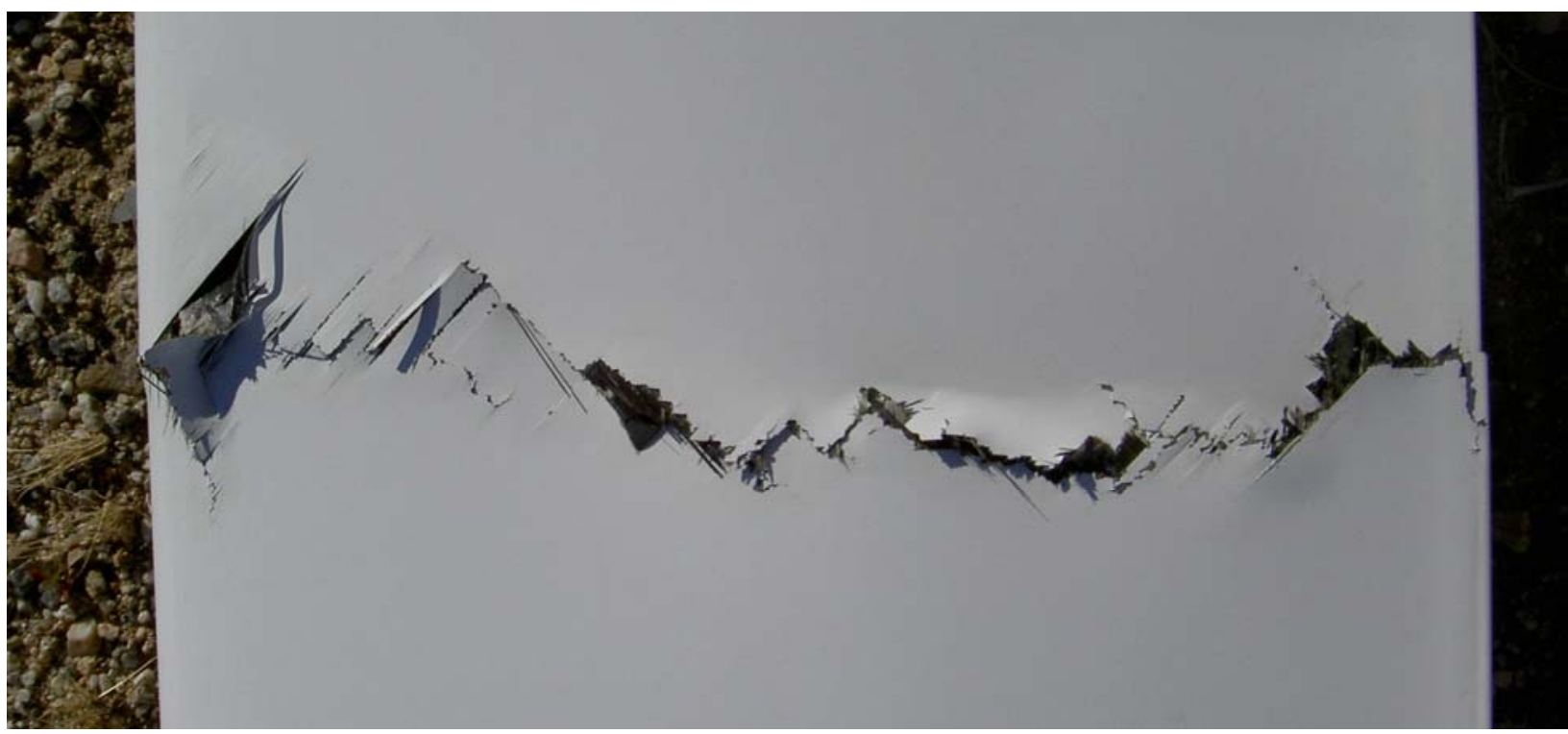

Figure 19. Upwind (tension) side of Set \#2 blade buckling failure shown in Fig 18. 


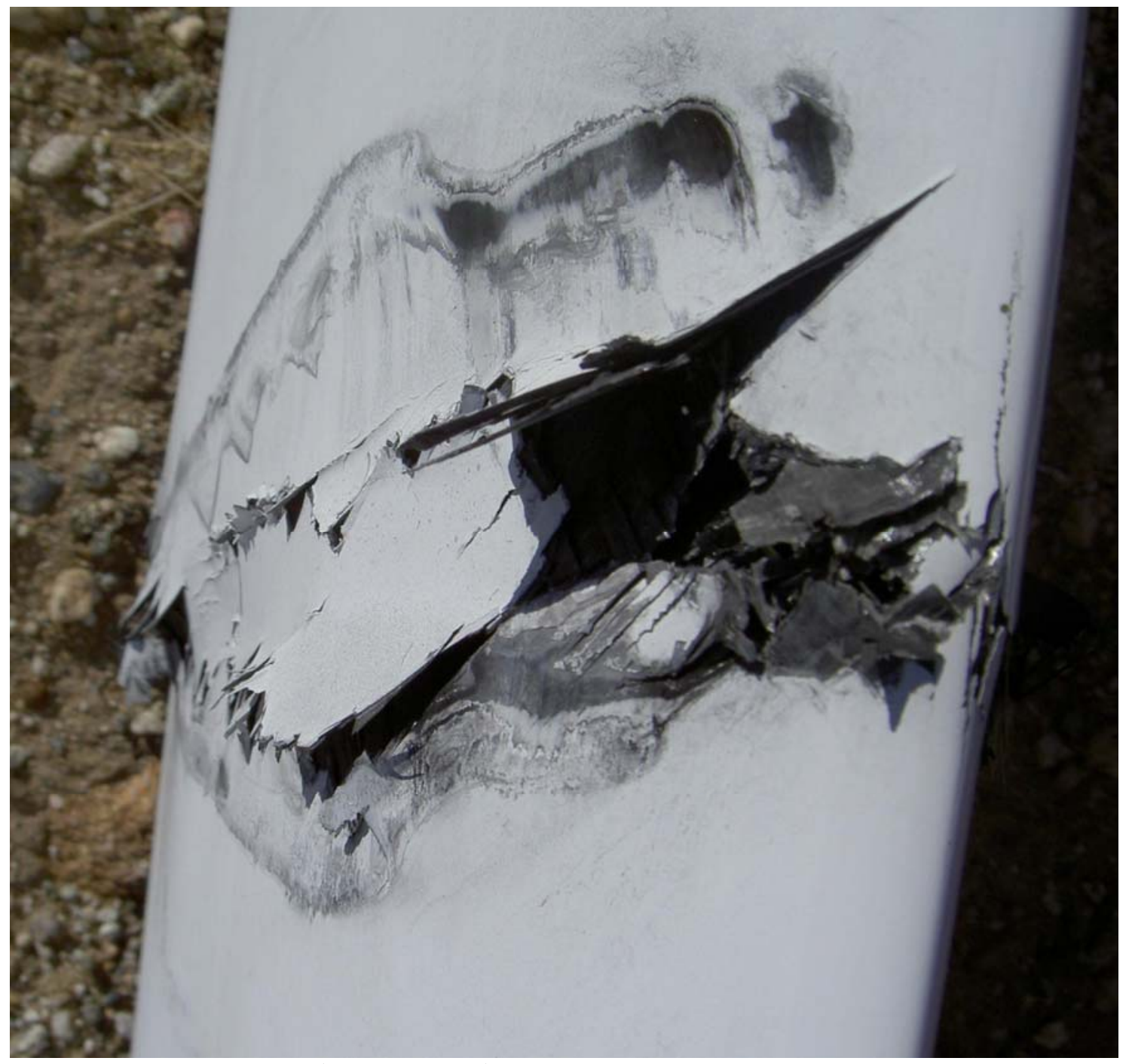

Figure 20. Downwind (compression) side of Set \#2 blade buckling failure shown in Fig. 18

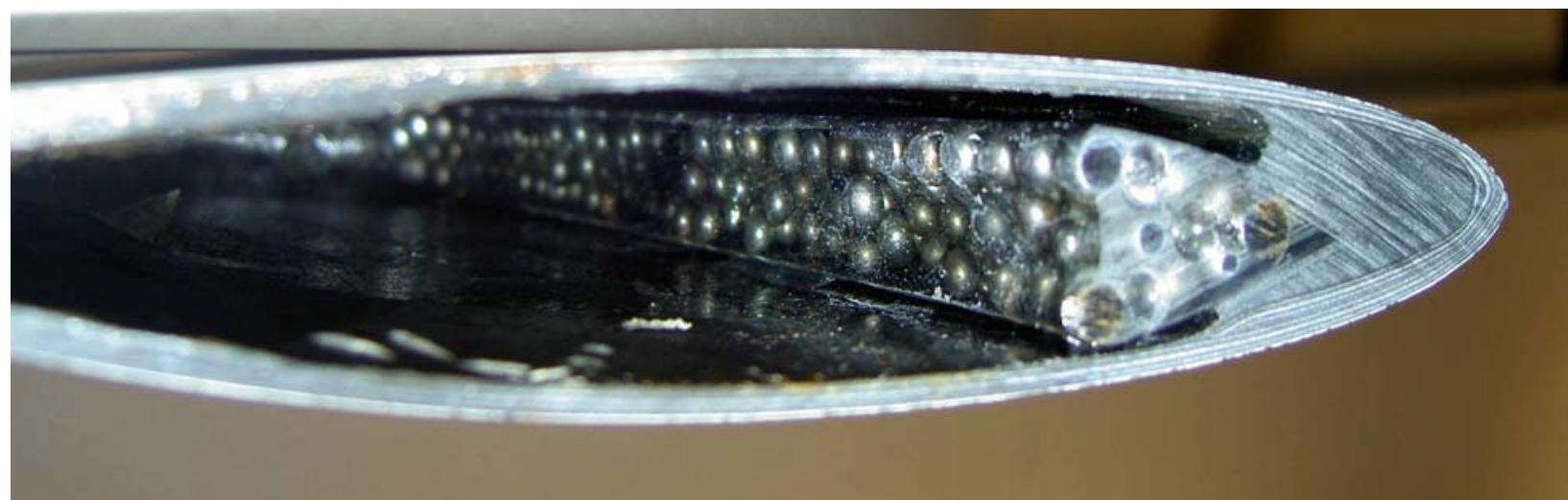

Figure 21. Leading Edge D-Spar (LEDS ) of failed Set \#2 blade 8" from tip of blade. LEDS was inserted into hollow blade shell and glued in place, LE down, after the blade shell was molded by HCBMP. Note puddle of cured epoxy at LE. LEDS was probably inserted too far into blade. LEDS in this position is not achieving chordwise mass balance at the quarter-chord point. 


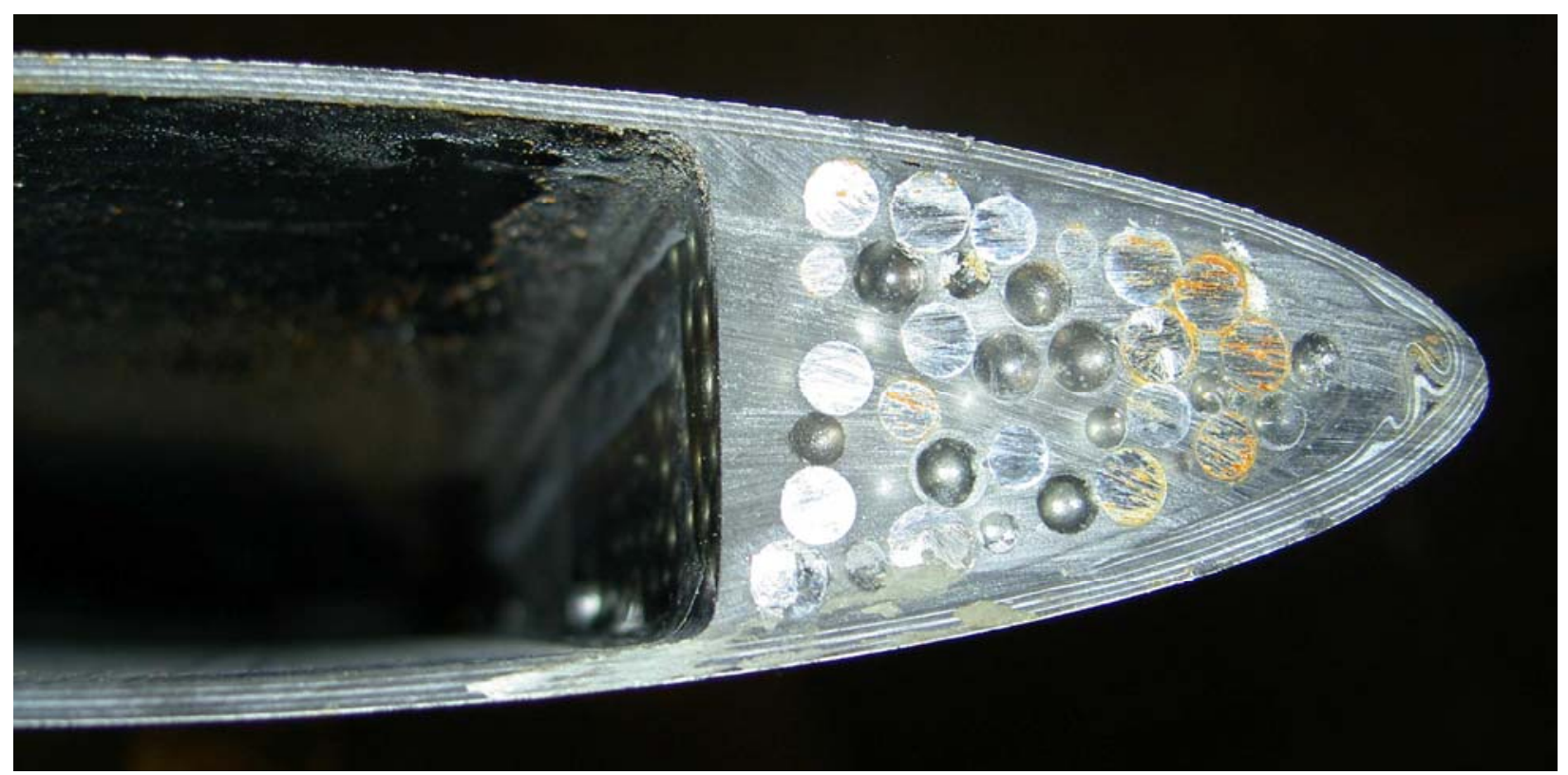

Figure 22. Leading Edge D-Spar (LEDS ) of failed Set \#2 blade 100" from tip of blade. LEDS was inserted into hollow blade shell and glued in place, LE down, after the blade shell was molded by HCBMP. Note small puddle of cured epoxy at LE, indicating that LEDS was not bottomed-out against the LE interior as the potting epoxy cured. LEDS was probably inserted too far into blade. LEDS in this position is not achieving chordwise mass balance at the quarter-chord point. Note wrinkle in plies at LE, but no voids.

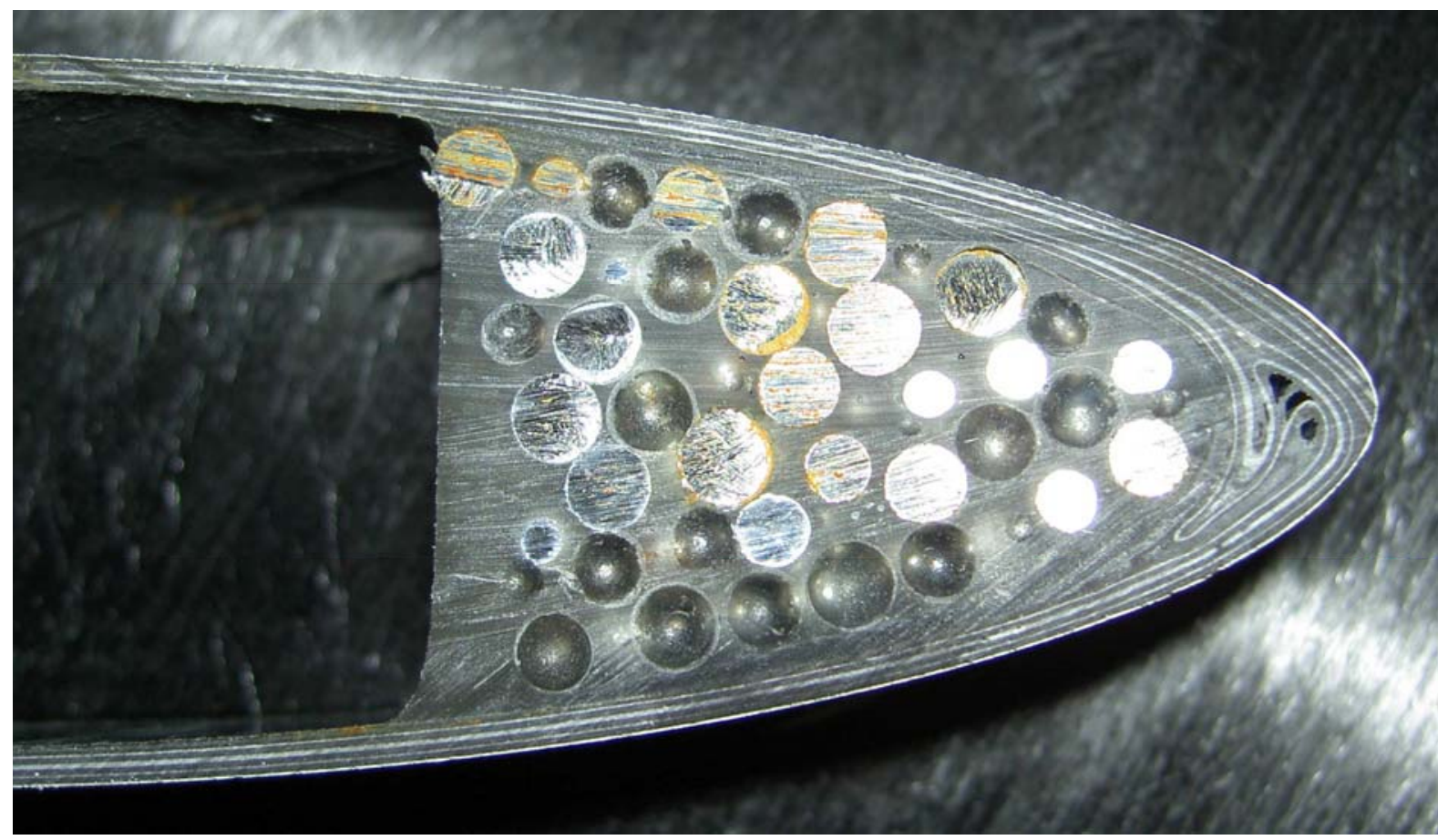

Figure 23. Leading Edge D-Spar (LEDS ) of failed Set \#2 blade 100" from tip of blade. LEDS was inserted into hollow blade shell and glued in place, LE down, after the blade shell was molded by HCBMP. Note small puddle of cured epoxy at LE, indicating that LEDS was not bottomed-out against the LE interior as the potting epoxy cured. LEDS was probably inserted too far into blade. LEDS in this position is not achieving chordwise mass balance at the quarter-chord point. Note wrinkle in plies at LE, with voids. 


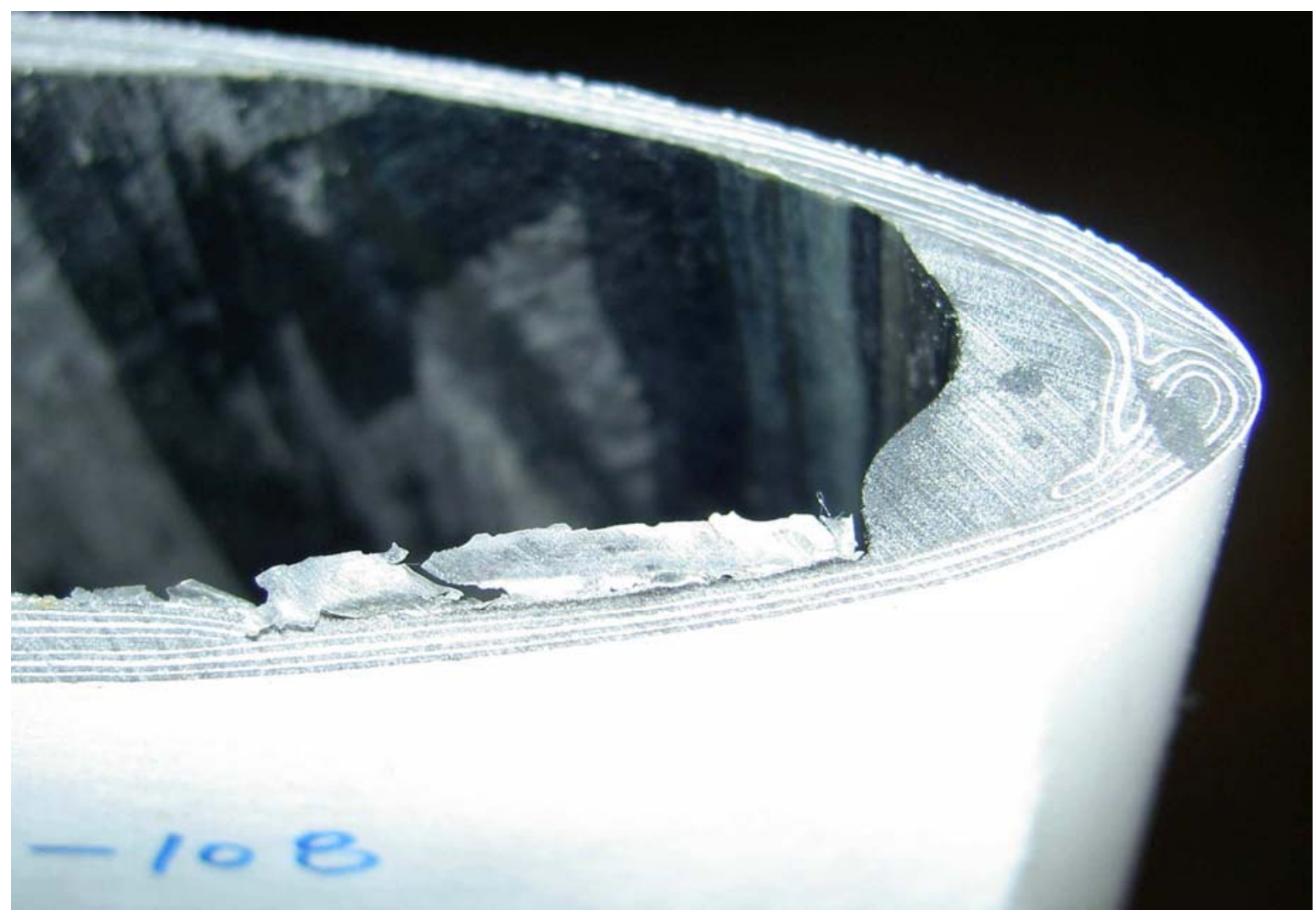

Figure 24. 108" from root end of failed Set \#2 blade. Note puddle of cured epoxy, intended to capture the LEDS, which has leaked past the dam at inboard end of LEDS.

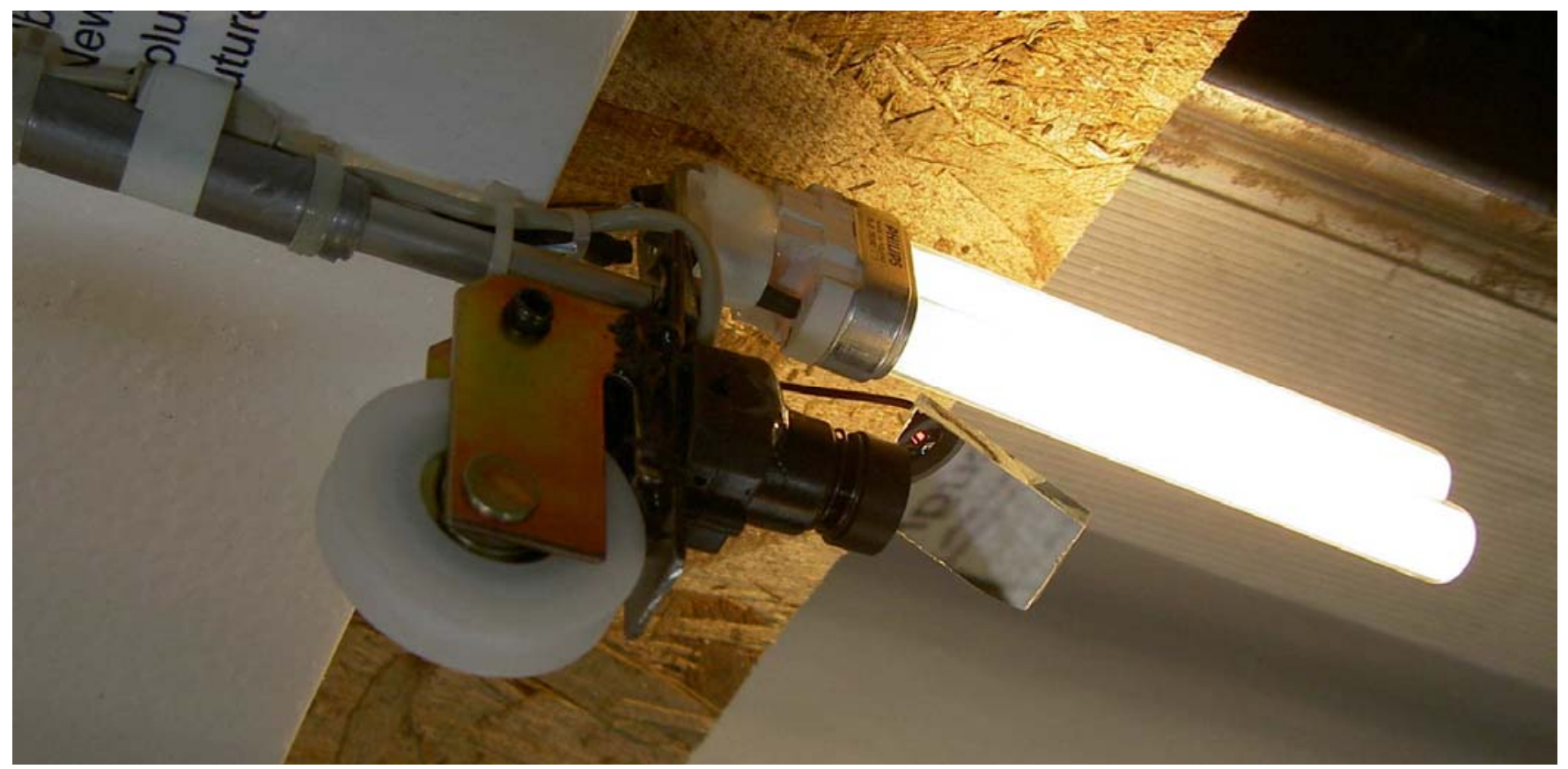

Figure 25. Miniature color TV camera, mirror, and fluorescent light for inspection of blade shell interior LE. Wheel rolls along the LE with blade horizontal, LE down. 


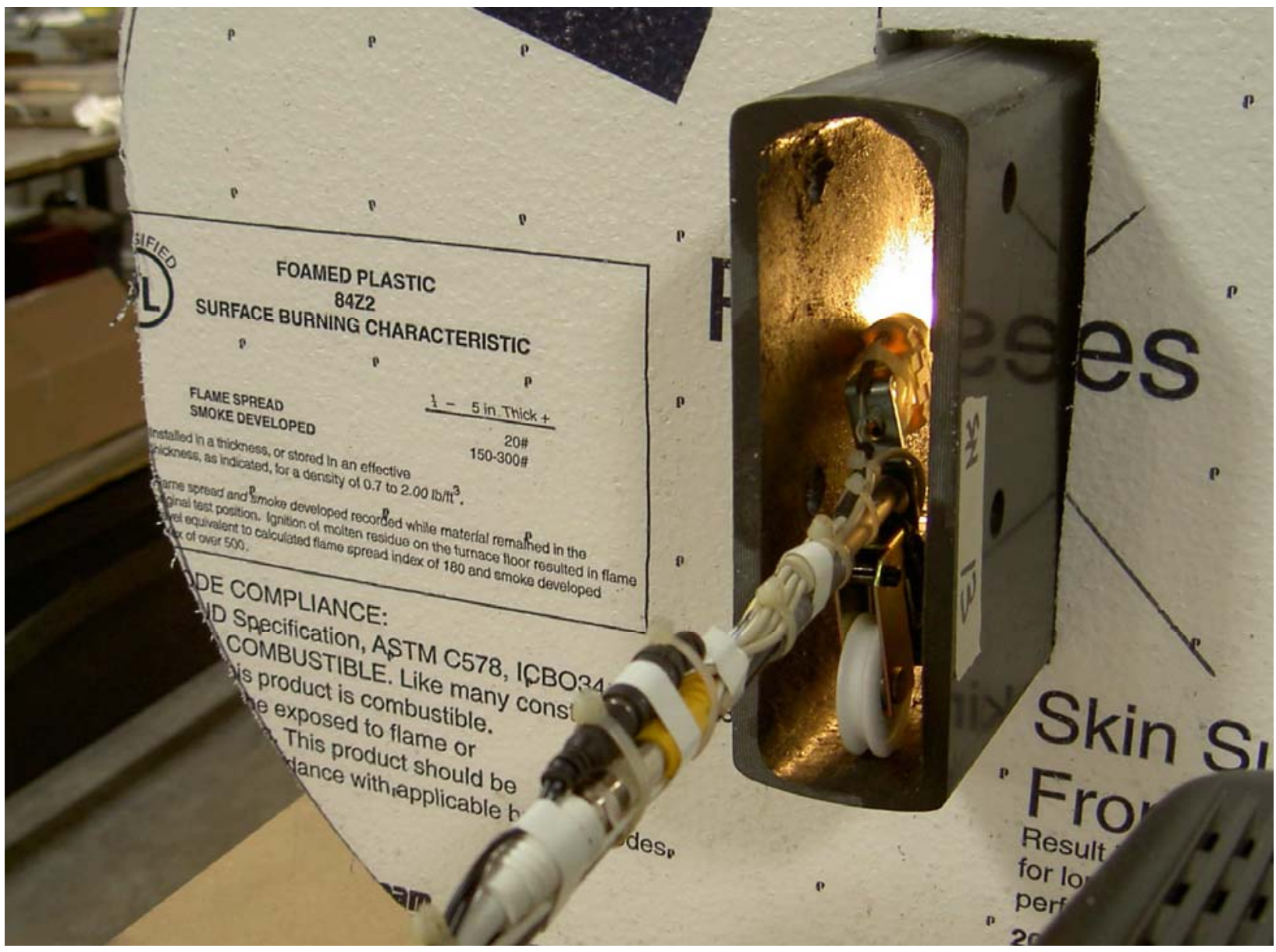

Figure 26. Inspection videocamera, shown in Fig. 25, enters blade shell SN 13, LE down. 


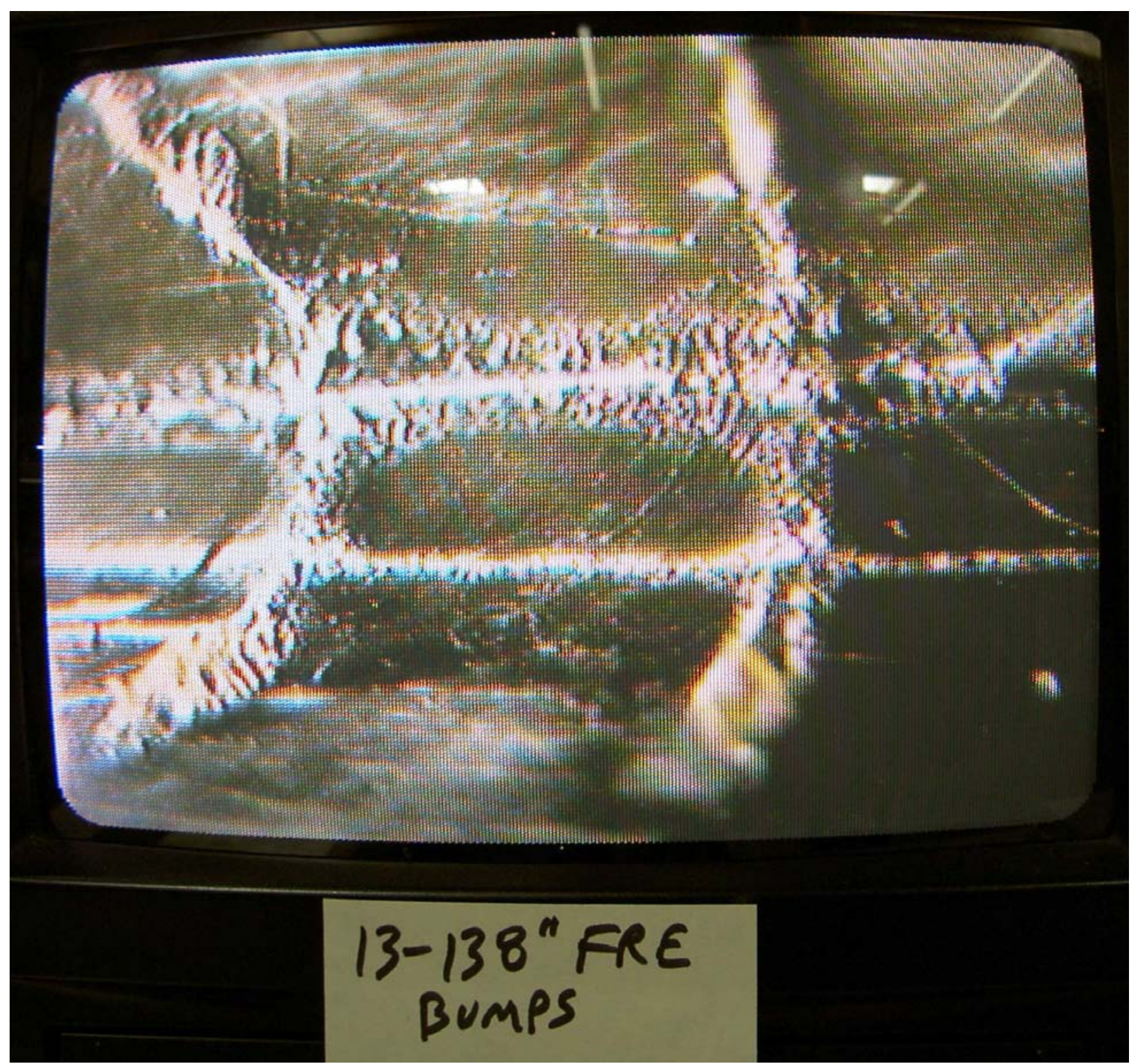

Figure 27. Blade SN 13, Set \#3, 138" from root end (FRE) of blade, showing "bumps" caused by wrinkles in the bladder, which will interfere with post-molding installation of the LEDS. From camera shown in Figs. 24, 25. 


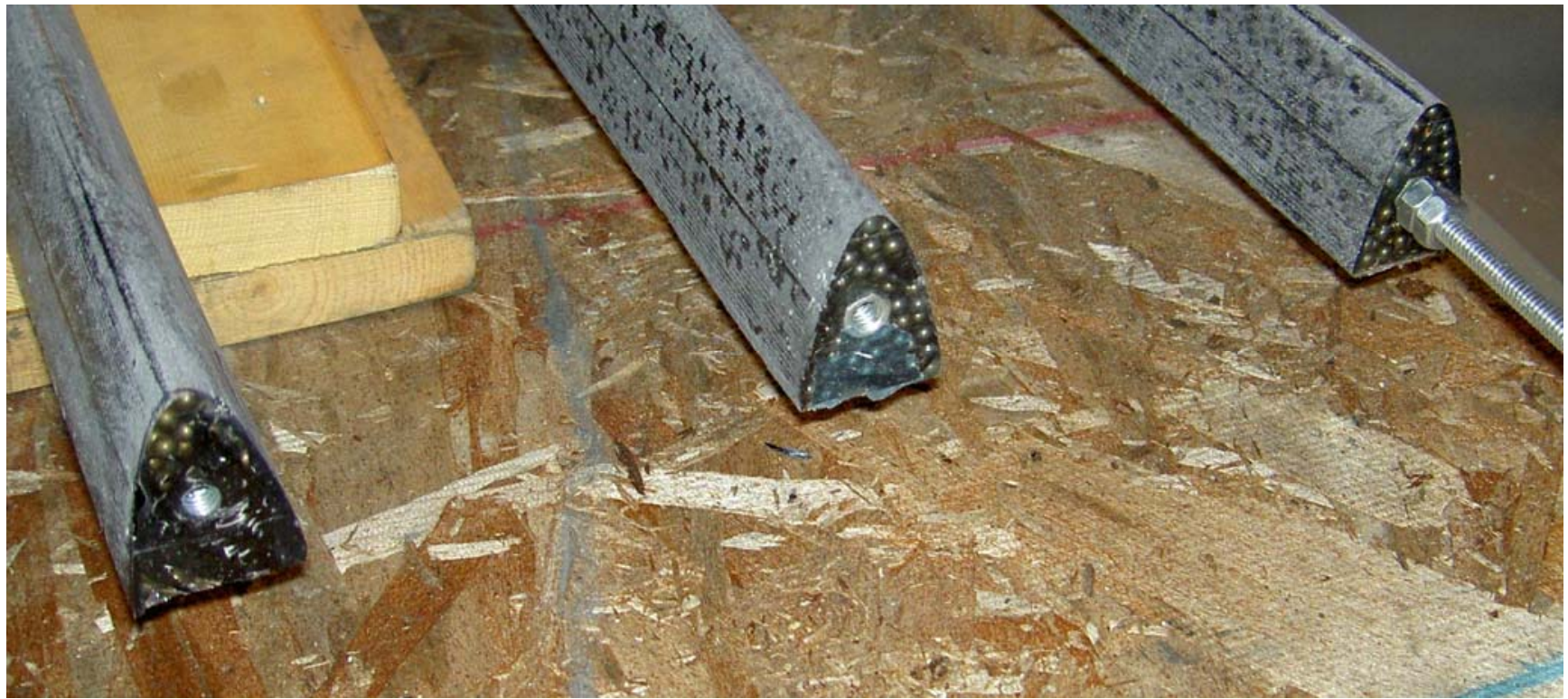

Figure 28. Inboard ends of LEDS's for Set \#3, before extensive grinding to allow installation. $1 / 4$ " allthread rod is removable insertion tool.

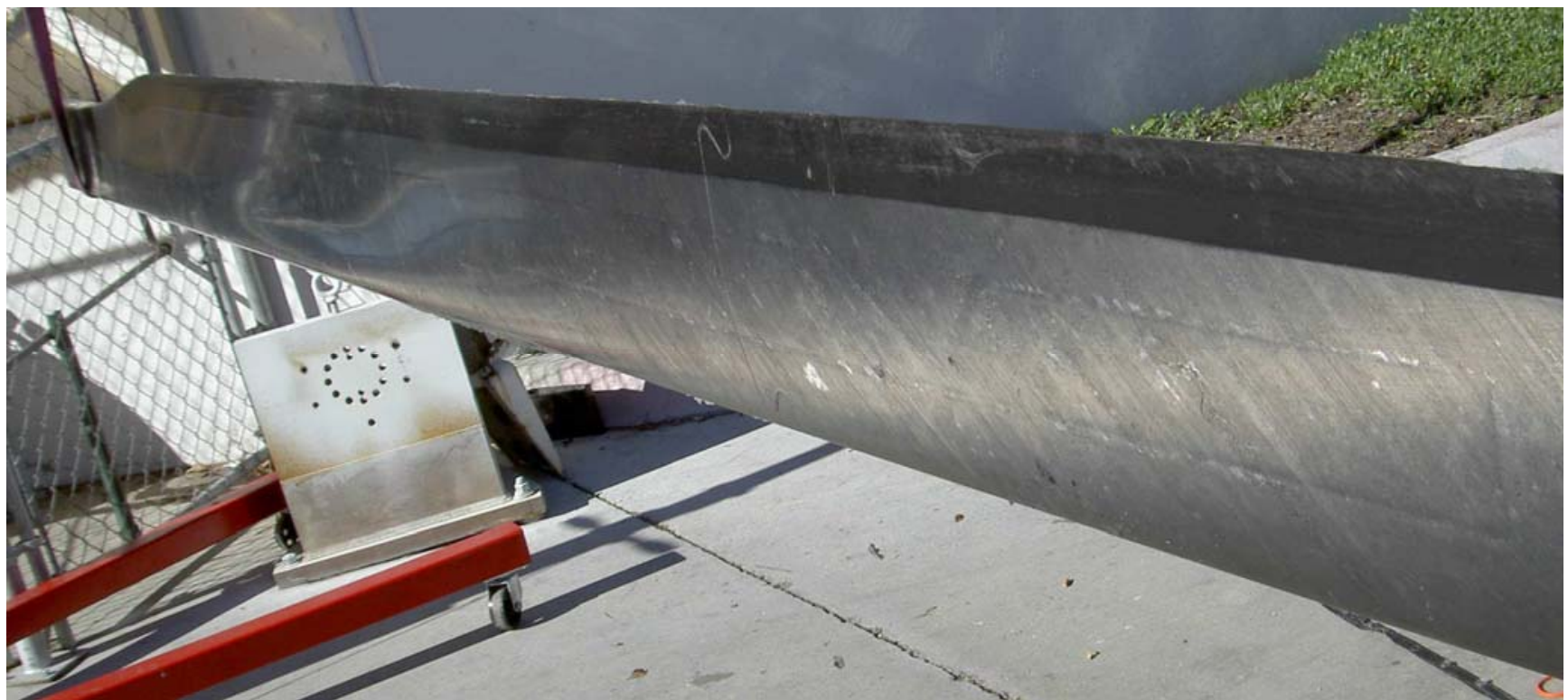

Figure 29. SN 12, Set 3, as-molded. Beginning the deflash, LE and TE shaping, and surface finish operations. Note light print-through of spanwise rectangular interior stiffening panel: 1/8" thick, 2" wide high-temp foam captured by the inner ply stack during prepreg layup operation. Note several dry spots in surface, where air or steam was trapped during cure cycly at $\sim 275 \mathrm{~F}$. 


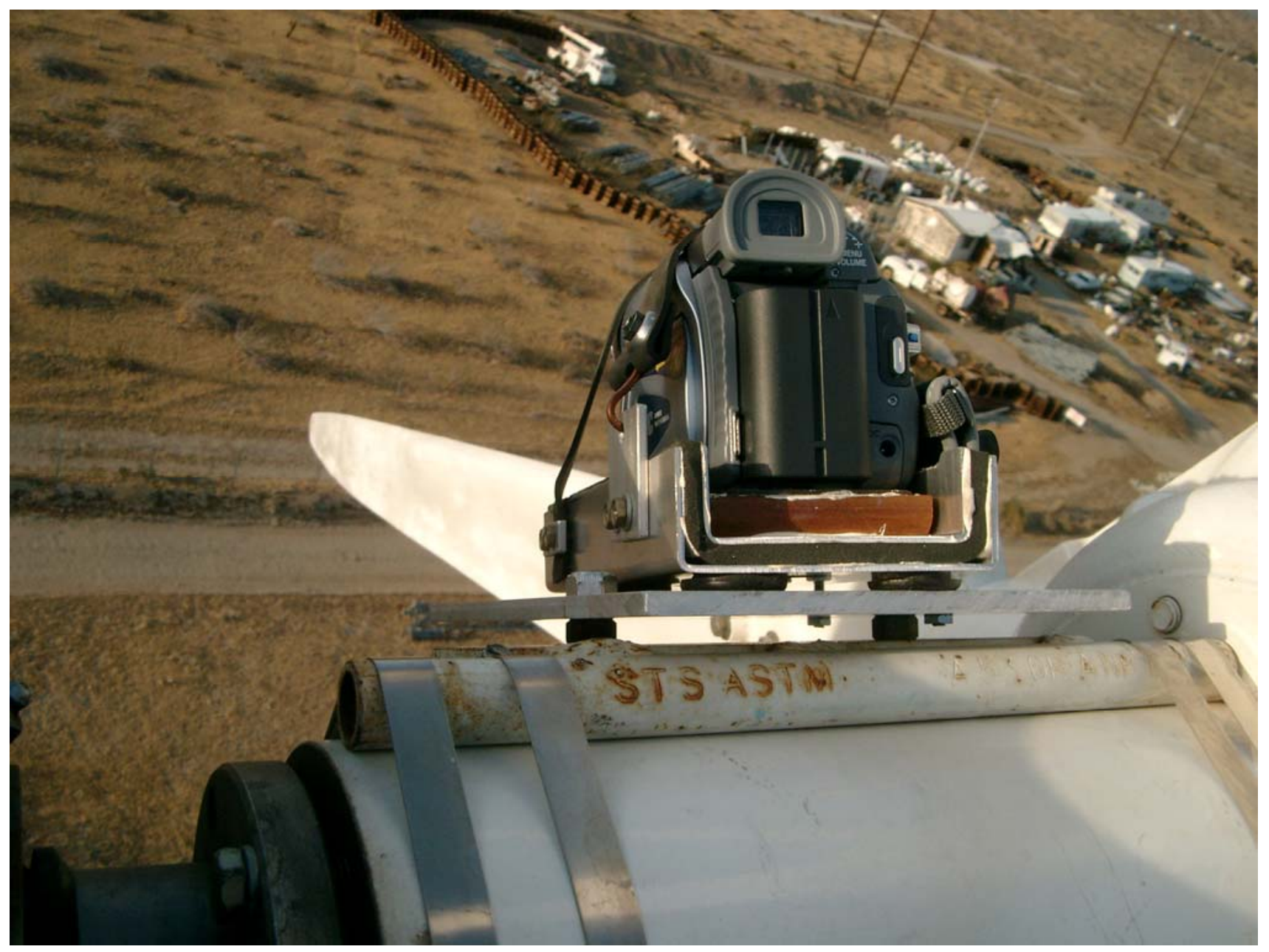

Figure 30. Hub-mounted digital videocamera for viewing whole blade, or blade mount - hub frame joint, during turbine operation. Set \#1, 19 Apr 04.

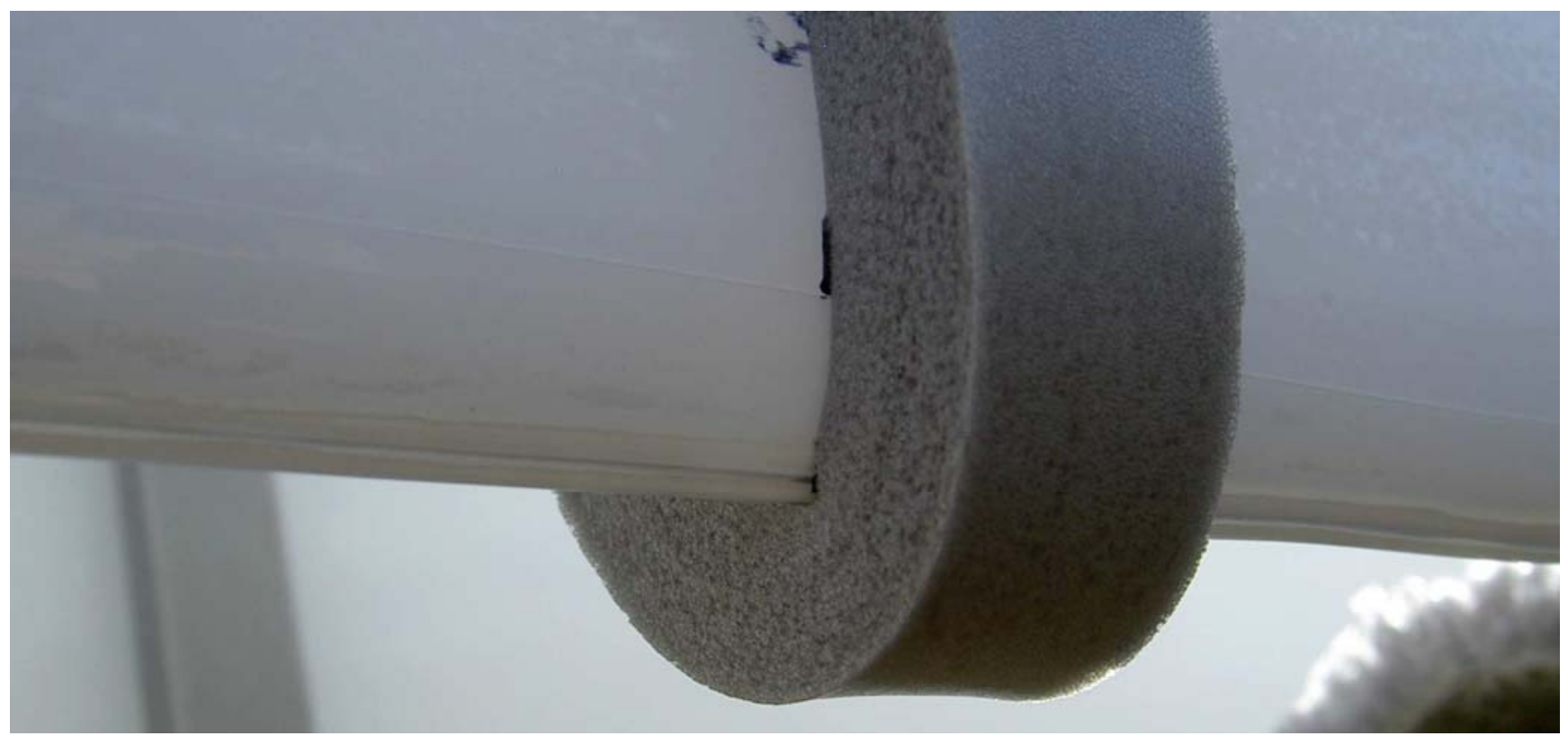

Figure 31. 15 Jan 05. Set \#3 typical LE showing mid-span foam dam and 0.068" diam nylon monofilament fishline captured under 8 mil 3M clear urethane "paint protection film" 


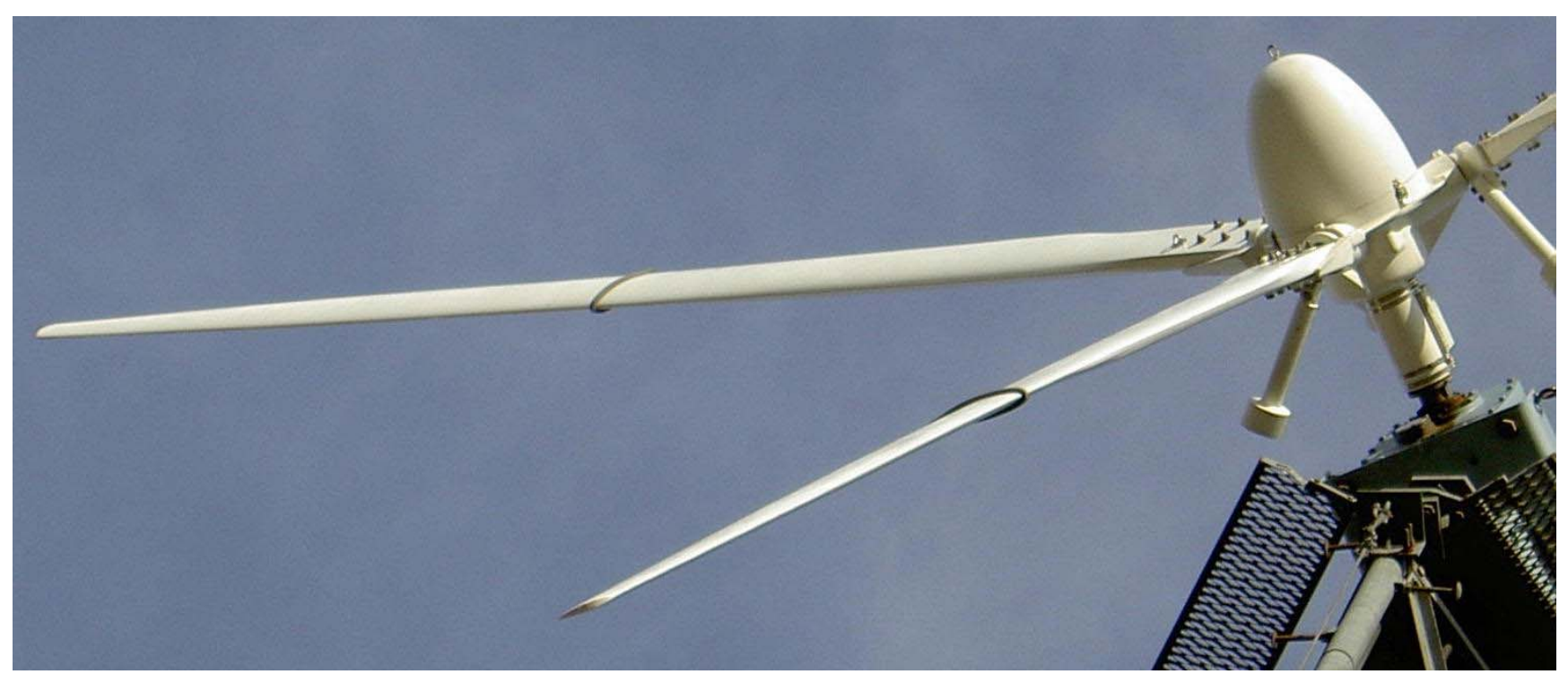

Figure 32. 15 Jan 05. Set \# 3 installed on B1 test machine. Mid-span foam dam visible on each blade. Modifications are attempt to induce stall regulation of power curve.

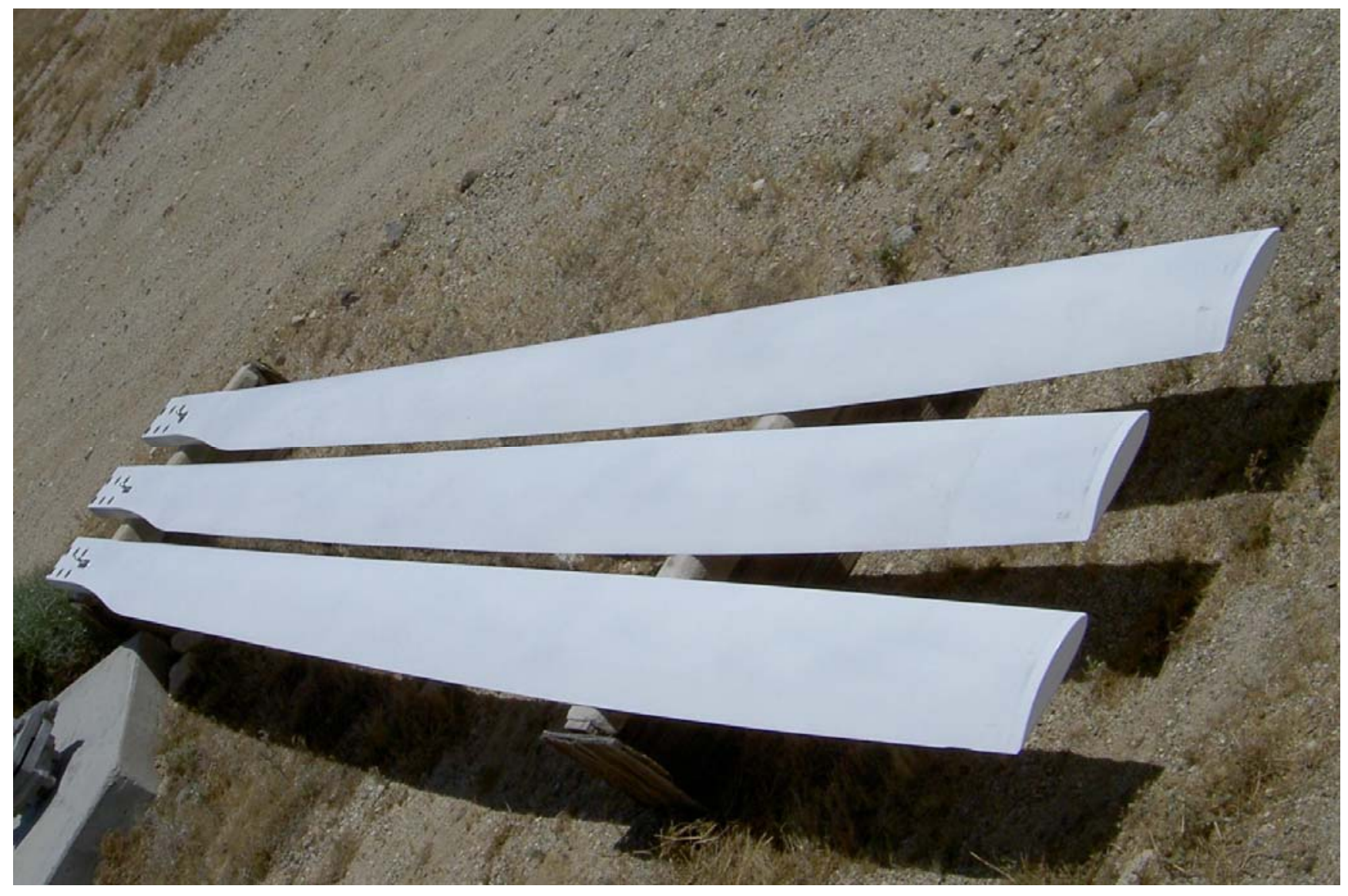

Figure 33. Blade set \#1 with $~ 1 \mathrm{~m}$ removed from tips. Ready to install on A26 machine. 

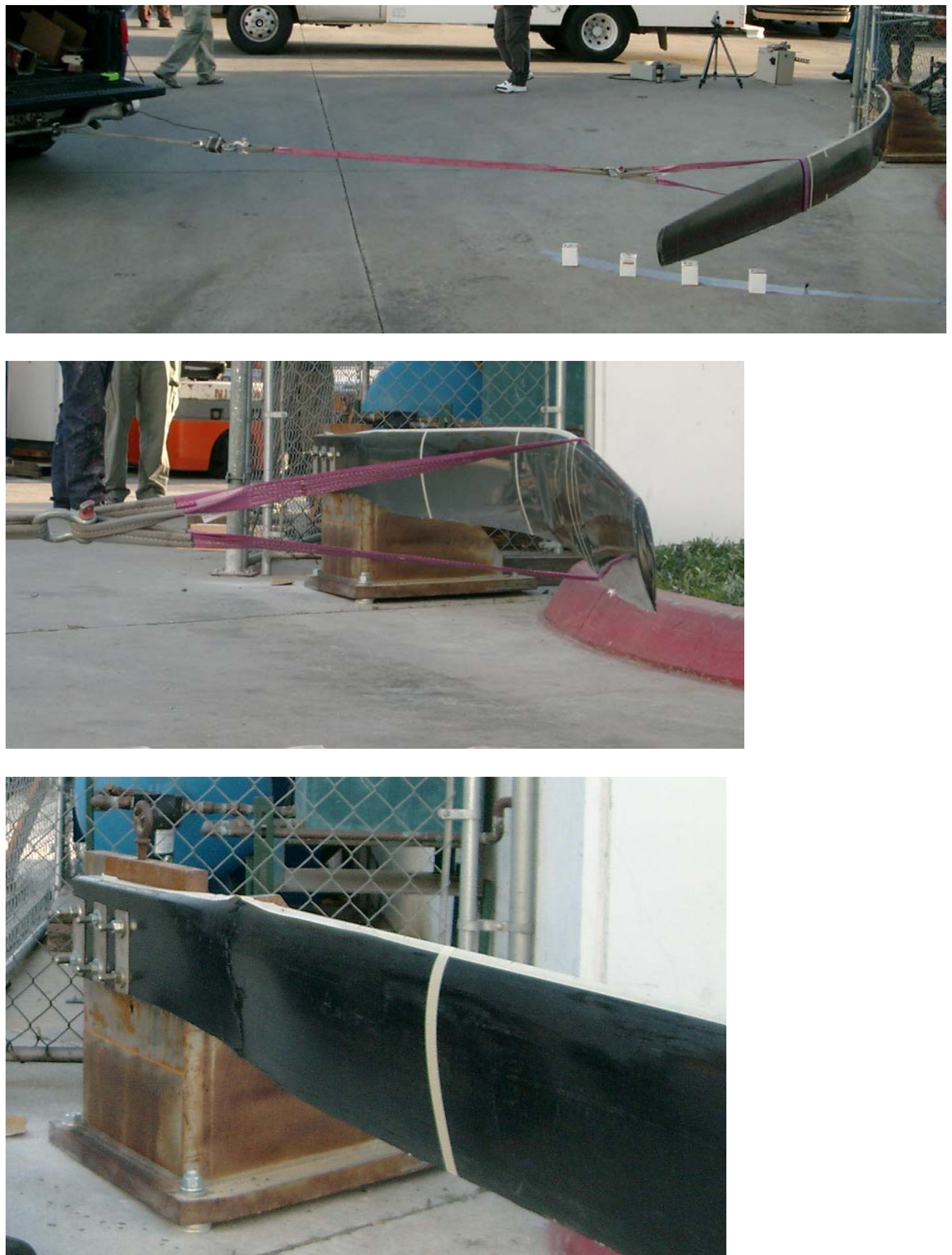

Figure 34. Flap stiffness and ultimate flap strength tests, SN1, 4 Mar 04, at QC 

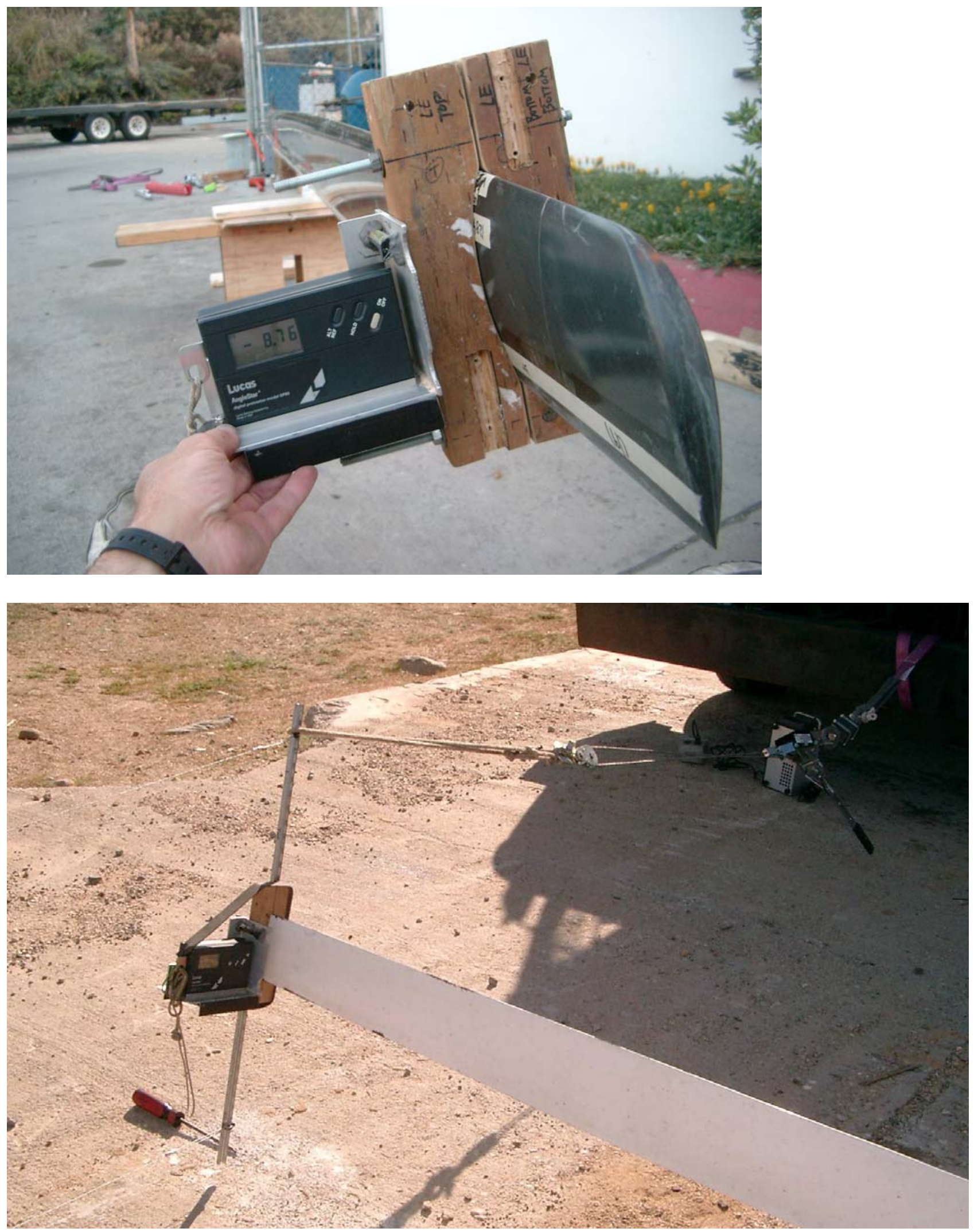

Figure 35. Torsional stiffness measurement with load cell, couple, digital protractor. 


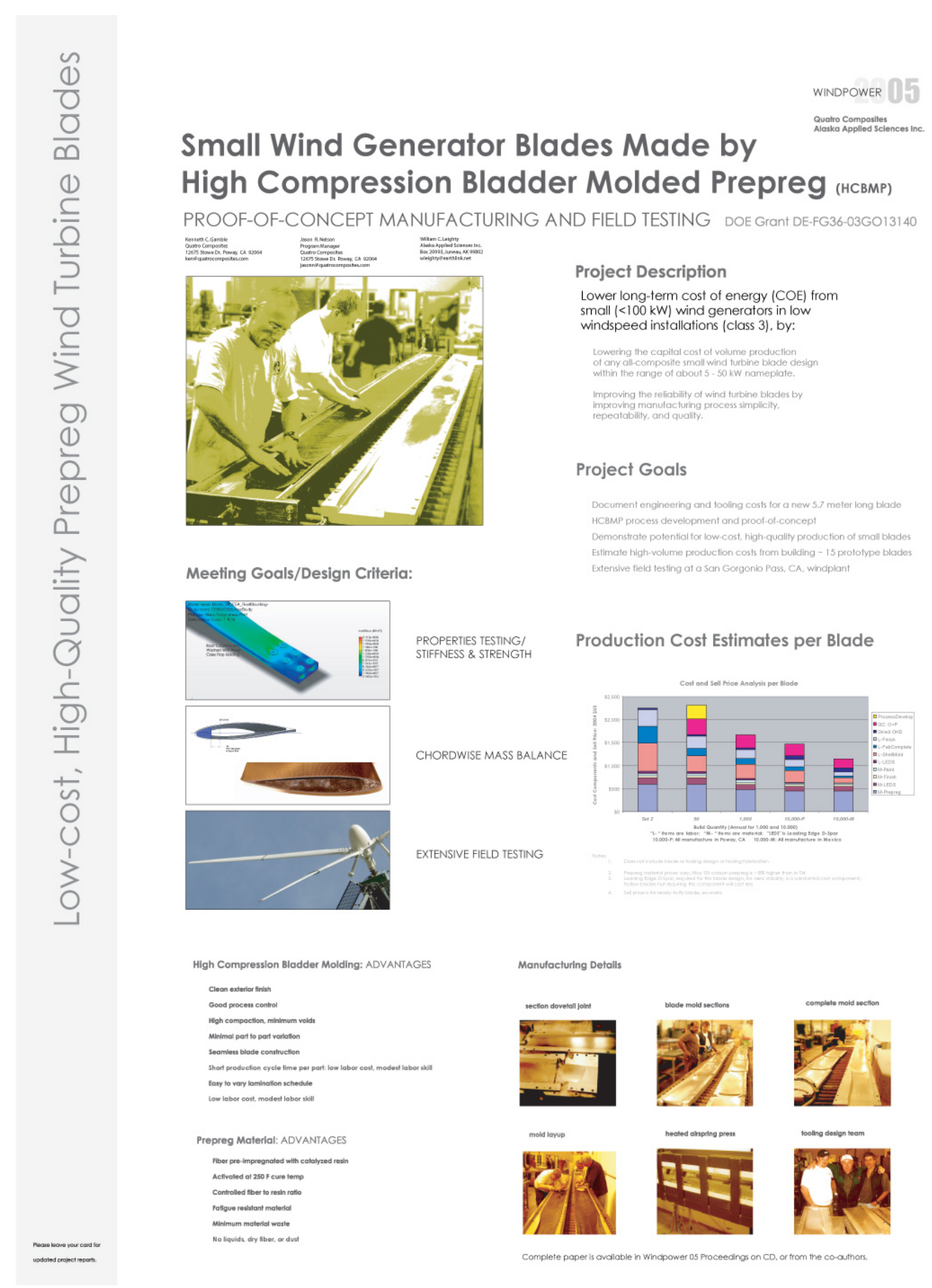

Figure 36. Poster presented at Windpower05, Denver, 15-18 May 05. The paper on this project is in conference proceedings, in Small Wind category. 


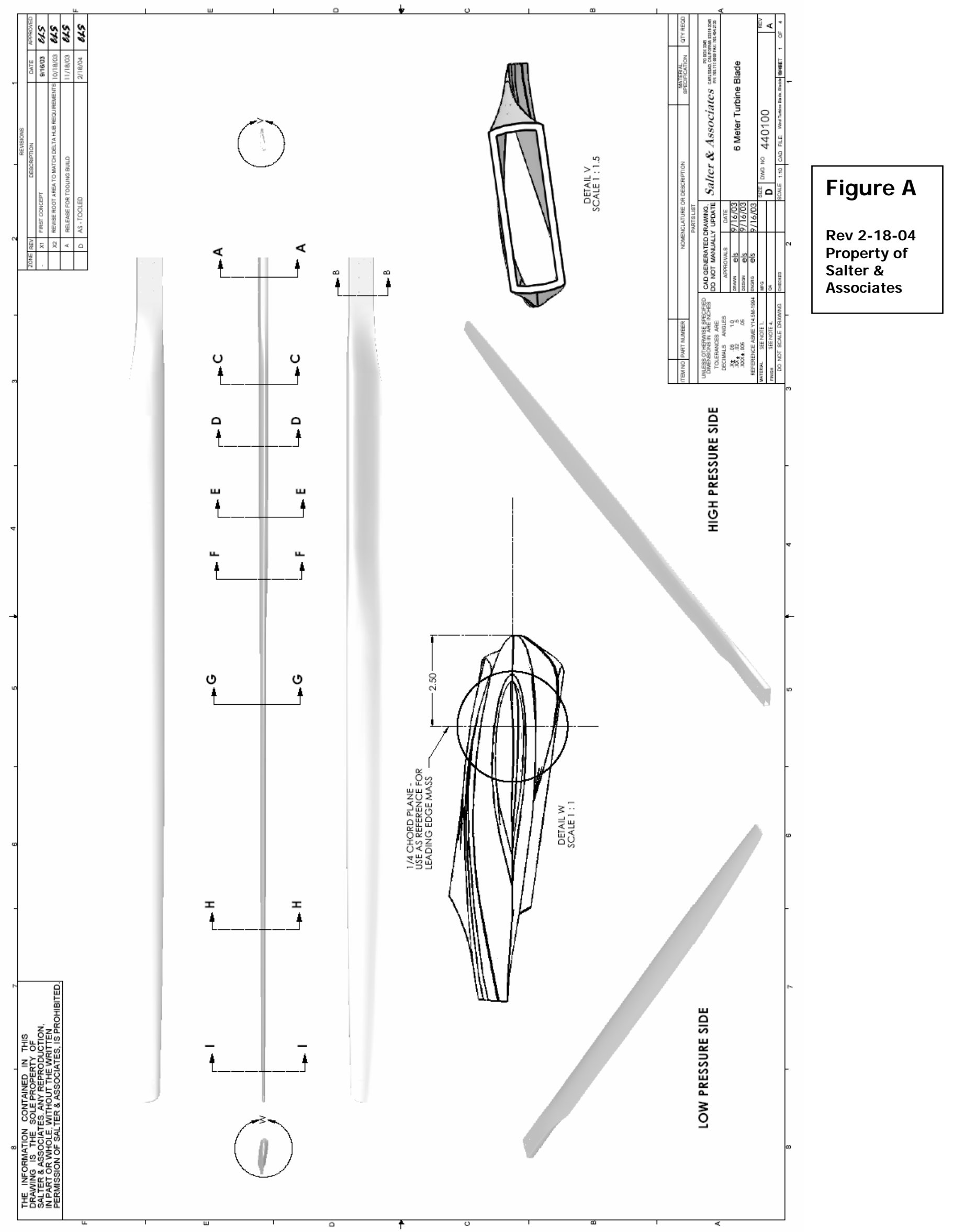




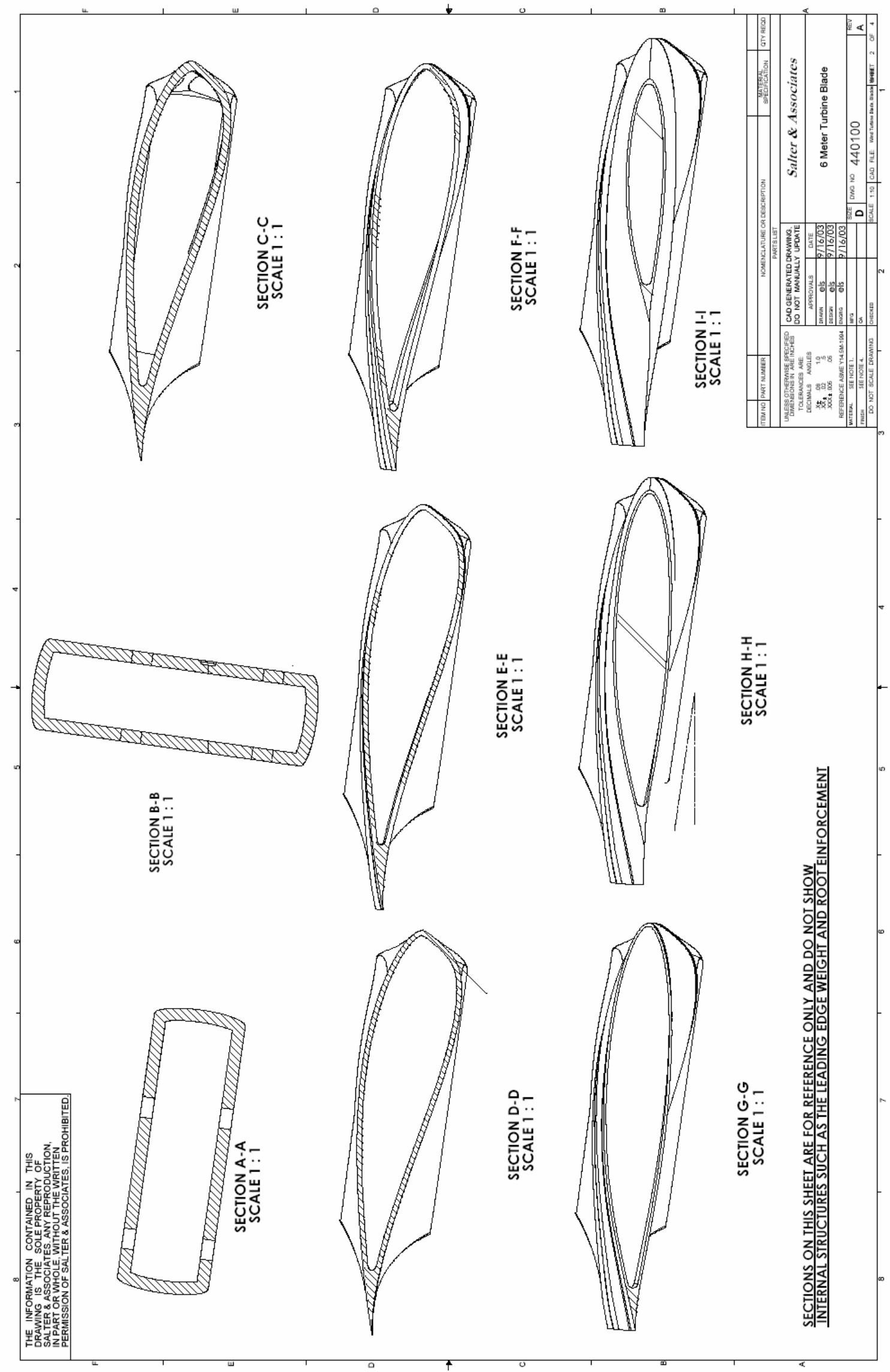

Figure B

Rev 2-18-04 Property of Salter \& Associates 


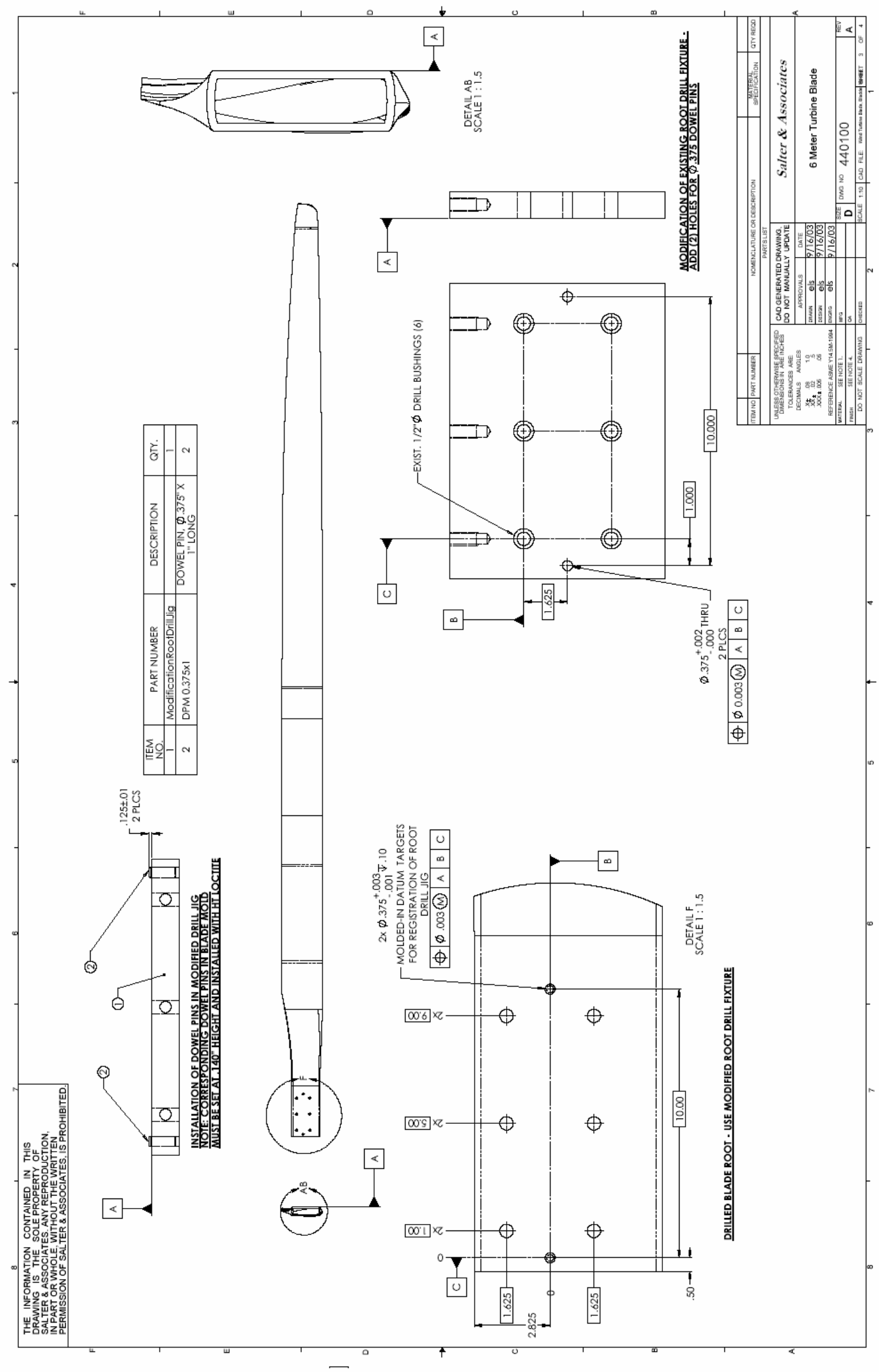

Figure C Rev 2-18-04 Property of Salter \& Associates 


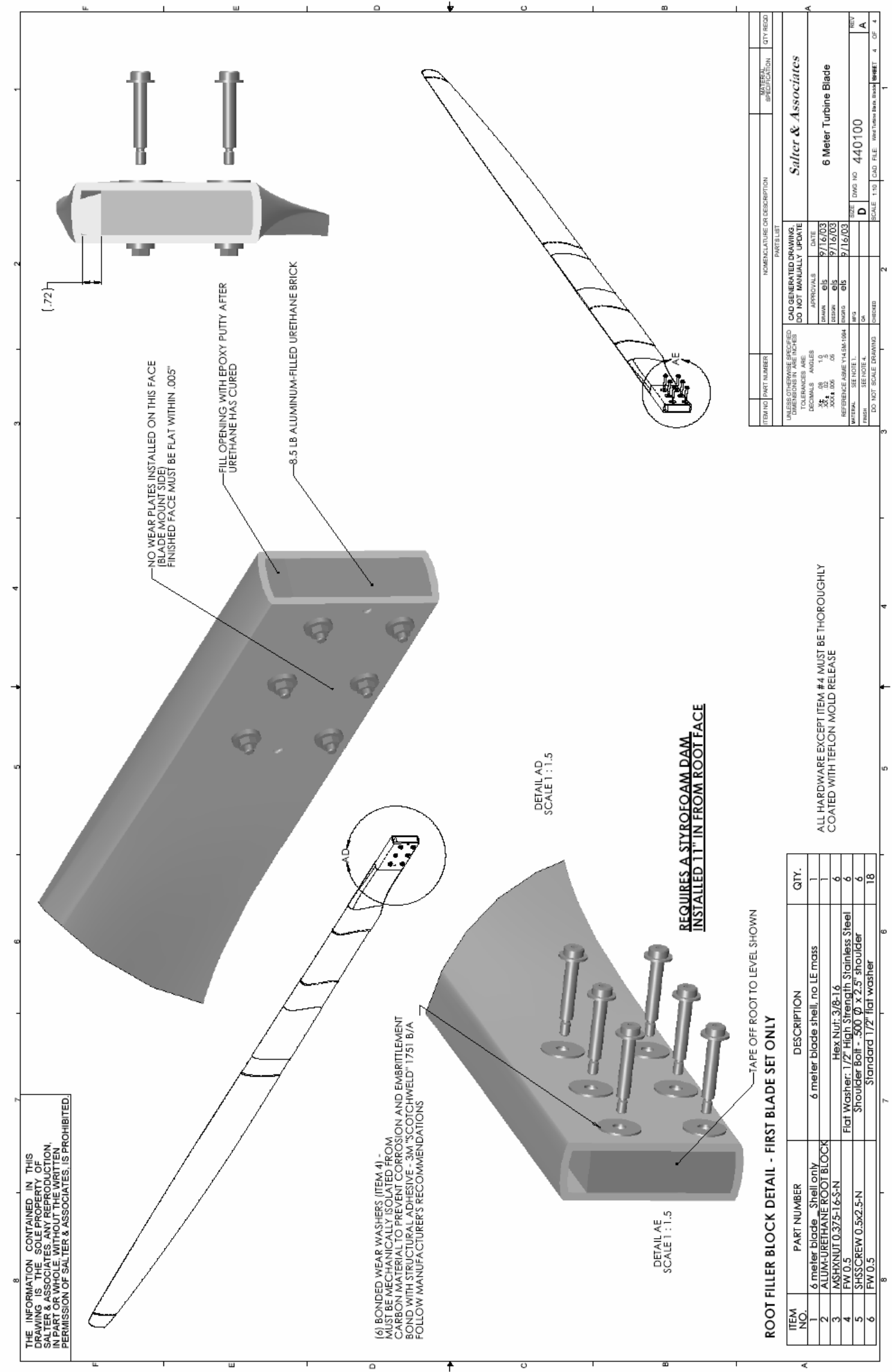

Figure D

Rev 2-18-04

Property of

Salter \&

Associates 


\section{Appendix

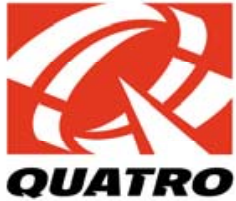

\section{FOR IMMEDIATE RELEASE}

June 30, 2005

Contact: Doug Roberts

Quatro Composites Corporation

12675 Stowe Drive

Poway, CA 92064

www.quatrocomposites.com

info@quatrocomposites.com

\section{Quatro Composites Corporation Commercializes High Compression Bladder Molding Prepreg Process (HCBMP) for Southwest Windpower's Whisper 500 wind turbine.}

Poway, California Southwest Windpower (Flagstaff, Arizona) has awarded a purchase order to Quatro Composites for the development and production of the redesigned Whisper 500 wind blades using Quatro's HCBMP process.

Southwest Windpower's Jean Lonjaret stated that, "We chose Quatro and the HCBMP process for our new Whisper 500 blades because we were very impressed with the cost-of-energy improvement (COE), fast cycle times, monocoque construction and excellent structural properties afforded by the process." He also stated that, "The Whisper 500 can produce enough energy to power an entire home. The Whisper 500 features a pair of 2 meter-long hybrid carbon/fiberglass blades and incorporates the patented side furling design that optimizes output at any wind speed. Assuming an average wind speed of $5.5 \mathrm{~m} / \mathrm{s}$, a Whisper 500 will produce as much as $500 \mathrm{kWh}$ per month.”

Quatro developed the HCBMP process for wind generator blades while working on a DOE grant from the National Renewal Energy Lab (NREL) in 2004. Quatro was chosen as subcontractor by prime contractor Alaska Applied Sciences Inc. (Juneau, AK). The objective of the grant was to exhibit the effectiveness of producing small-to-medium sized wind generator blades by using an inflatable bladder to mold prepreg in a female closed-cavity mold. Bill Leighty from Alaska Applied Sciences stated, "The program was a success. We proved the potential of the HCBMP process by producing and flying multiple blade sets on existing turbines in Palm Springs California.” Each blade is 19 feet long and has a max width (chord) of 10”.

"We were able to effectively produce a 19 foot blade, but we found that the HCBMP process is really more suitable for wind blades less than 10 feet in length." said Doug Roberts of Quatro Composites. "We are very excited about the potential of the HCBMP process for the sub $10 \mathrm{~kW}$ wind turbine market." Quatro is actively pursuing additional business in this market segment.

Quatro Composites specializes in compression and bladder molding of prepreg materials, including carbon, glass, and aramid fibers. Markets served are: medical, space, aerospace, defense, wind energy, automotive, sporting goods, and audio. Rapid product development is Quatro's focus and strength. Product development and manufacturing is performed in Poway, California. Commercial and sporting goods products are manufactured in Xiamen, China.

For information: www.quatrocomposites.com

Contact:info@quatrocomposites.com

Phone: 858-513-4300 x 108 